\title{
Bioresorbable Collagen Membranes for Guided Bone Regeneration
}

\author{
Haim Tal, Ofer Moses, Avital Kozlovsky \\ and Carlos Nemcovsky \\ Department of Periodontology and Implantology, \\ Tel Aviv University \\ Israel
}

\section{Introduction}

Localized lack of bone volume in the jaws may be due to congenital, post-traumatic, postsurgical defects or different disease processes. Increasing the bone volume has long been an attractive field of basic and clinical research. The introduction of implant therapy, and the proven relationship between long-term prognosis of dental implants and adequate bone volume at the implant site (Lekholm et al. 1986), dramatically increased the interest of both clinicians and scientists in this field, making augmentation procedures an important part of contemporary implant therapy. Basically, four methods have been described to augment bone volume: a. osteoinduction, using appropriate growth factors (Reddi 1981; Urist 1965); b. osteoconduction, using grafting materials that serve as scaffolds for new bone growth (Buch et al. 1986; Reddi et al. 1987); c. distraction osteogenesis, by which a surgically induced bone fracture enables slow controlled pulling apart of the separated bone fragments (Ilizarov 1989a,b); d. guided bone regeneration, which allows selective bone tissue growth into a space maintained by tissue barriers (Dahlin et al. 1988, 1991a; Kostopoulos \& Karring 1994; Nyman \& Lang 1994). Among the different methods, guided bone regeneration (GBR) is the most popular and best documented for the treatment of localized bone defects in the jaws, probably due to its relative simplicity of use while allowing the placement of endosseous implants in areas of the jaw with bony defects and/or insufficient bone volume. Highly predictable success rates can be achieved using GBR; in fact, it has been shown that success rates of implants placed at GBR treated sites and sites without bone augmentation are comparable (Hammerle et al. 2002).

Guided Tissue Regeneration (GTR) has been introduced into clinical dental practice over 30 years ago, soon after Melcher (1970,1976), followed by Karring et al. 1980 and Nyman et al. 1980, presented its basic principles to the professional community. The mechanisms of GBR generally followed the same principles i.e. that under certain conditions, cells that originate from tissues adjacent to an exclusively provided space are able to form their parent tissue. In order to allow exclusive repopulation of cells from desired tissues into that space, preference must be given by preventing access of cells from neighboring undesired tissues using tissue barriers, commonly referred to as membranes (Figs. 1,2). 


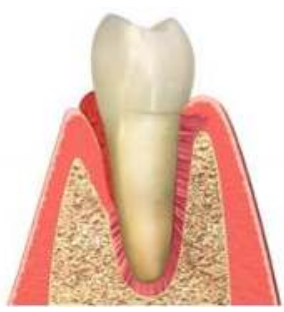

a.

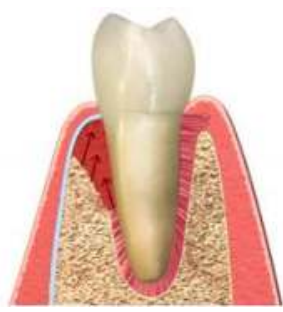

b.

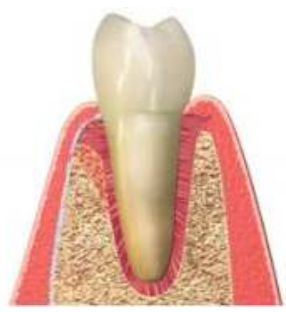

C.

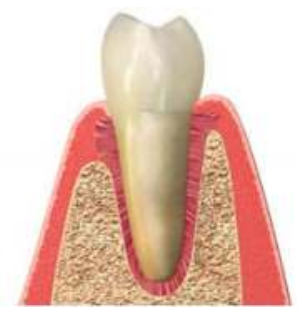

d.

Fig. 1. Guided tissue regeneration scheme describing the use of a resorbable barrier membrane. a. vertical periodontal lesion in the mandible $b$. resorbable membrane is stabilized over the debrided lesion and covered by the mucosal flap c. after 3- 5 months the membrane starts to resorb; new bone, new periodontal ligament and new cementum are visible d. reestablishment of most of the periodontal attachment apparatus is completed.

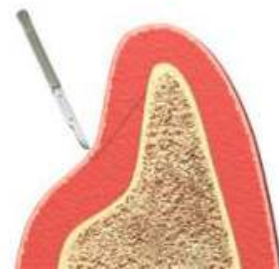

a.

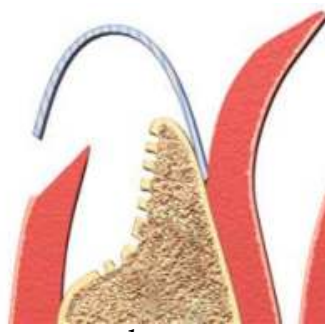

b.

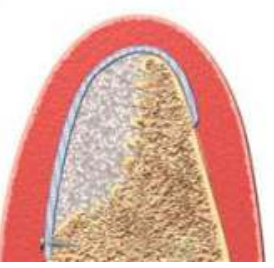

C.

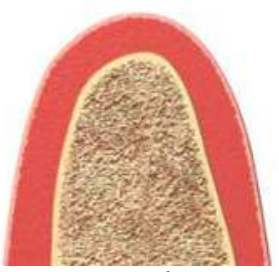

d.

Fig. 2. Guided bone regeneration scheme describing the use of a resorbable barrier membrane. a. bony defect is diagnosed $b$. the defect is debrided, bone cortex is perforated, membrane supporting scaffold material and a membrane are placed. c. the membrane is stabilized and shaped to dictate the desired bone contours $\mathrm{d}$. a few months later bone regeneration is observed restoring the desired shape of the jaw.

\section{Tissue barriers}

A wide range of tissue barrier materials has been used in experimental and clinical studies in GTR/GBR procedures, including polytetrafluoroethylene (PTFE), expanded PTFE (ePTFE), polyglactin 910, polylactic acid, polyglycolic acid, polyorthoester, polyurethane, polyhydroxybutyrate, calcium sulfate, freeze-dried fascia lata,freeze-dried dura mater allografts, native and/or synthetic collagen, micro titanium mesh, and titanium foils. Among the requirements set for GTR/GBR devices are safety and effectiveness. Based on the strict criteria applied to cosmetic/plastic medicine, where no life threatening conditions are involved, documentation of the effectiveness of the procedures and materials should be available while at the same time adverse effects emerging from the implanted devices should be kept to a minimum. In 1994, Hardwick et al. formulated a list of criteria for tissue barriers used for GTR; these may also be applied for barriers used for GBR. Briefly, the main essential qualities expected are: a. biocompatibility, b. cell occlusiveness, c. integration by the host tissues, d. clinical manageability and ease to apply, e. space making ability. Since bioabsorbable and biodegradable barriers are degraded in vivo and are absorbed by the 
body, another additional two requirements need to be fulfilled for these, i.e. that tissue reactions resulting from the resorption of the barriers and it's by-products should be minimal and reversible and that the regenerative process should not be negatively affected (Gottlow 1993). There are a number of factors which are critical for the success or failure of GTR/GBR; these include membrane stability, duration of barrier function, ample blood fill of the area for regeneration, enhanced access of bone and bone marrow-derived cells to that space, and prevention of soft tissue dehiscences over the membrane.

Tissue barriers may be classified according to several criteria. For the purpose of this chapter, however, tissue barriers are divided into two main groups: non-resorbable and resorbable. Briefly, non-resorbable barriers are made of thin sheets of materials, mainly polymers. They are stable, non-degradable and biocompatible. The earliest commercial and most popular non-resorbable membranes were expanded polytetrafluoroethylene (ePTFE) membranes; these became a standard for bone regeneration shortly after GBR has been recognized as accepted dental therapy. Expanded PTFE is a polymer with high stability in biologic systems. It resists breakdown by host tissues and by microbes and does not elicit immunologic reactions (Fig. 3). The main limitation of ePTFE and other non

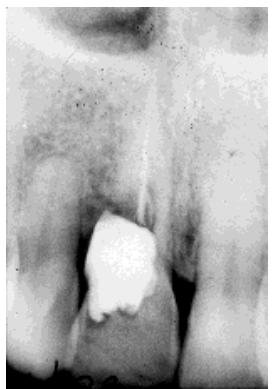

a.

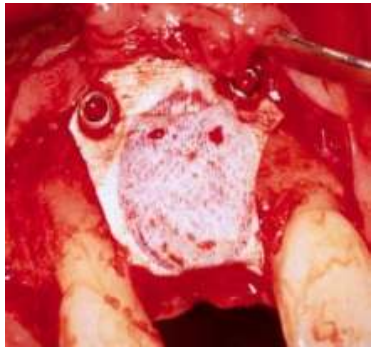

d.

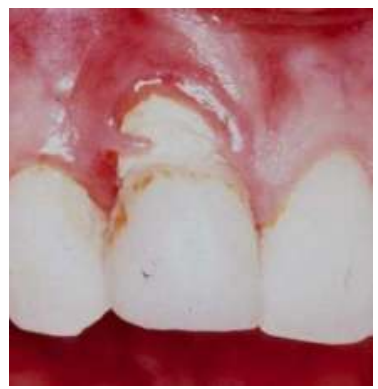

b.

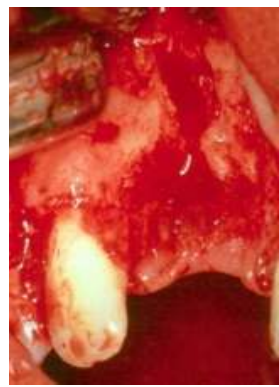

c.

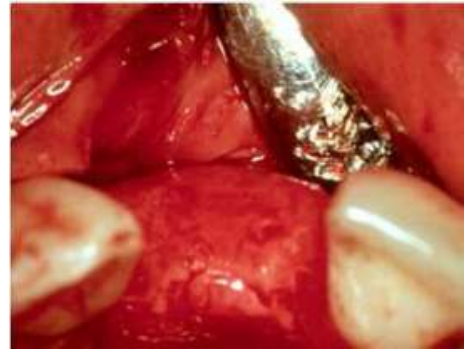

e.

Fig. 3. Successful GBR procedure aimed for implant site development using ePTFE membrane. a. radiographic view showing secondary caries and root resorbtion indicate extraction of the upper right central incisor $b$. clinical view and examination support the radiographic findings c. extraction of the tooth reveals significant bone loss at the esthetic zone d. guided bone regeneration using e-PTFE membrane stabilized by two buccal and one palatal titanium screws, and by demineralized freezed dried bone allograft supporting the sub-membraneous space. e. six months following the procedure the membrane is removed presenting adequate Bone volume and proper contours for an implant supported fixed restoration. 
resorbable membranes is the need for an additional surgery for membrane retrieval. Nonresorbable membranes have to be removed during a second surgical intervention imposing significant additional morbidity on the patient and additional risk for tissue damage.

A frequent complication associated with non-resorbable membranes is soft tissue dehiscense and membrane exposure; these may be followed by infection. Animal experiments (Gotfredsen et al. 1993; Kohal et al. 1999a) and clinical studies (Gher et al. 1994; Simion et al.1994; Hämmerle et al. 1998) have shown that premature membrane exposure and wound dehiscence impair the amount of bone regeneration. Figure 4 presents the exposure and removal of an infected e-PTFE membrane.

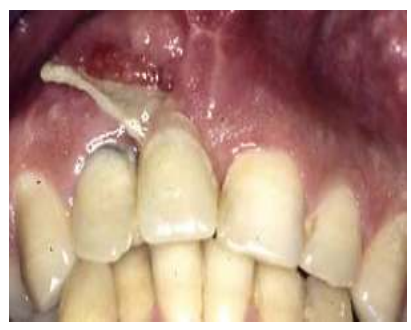

a.

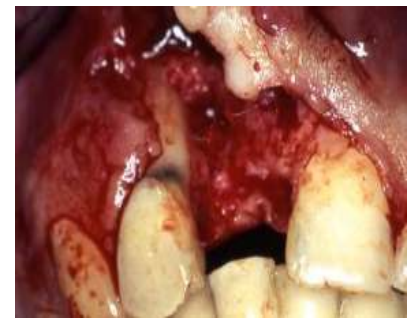

b.

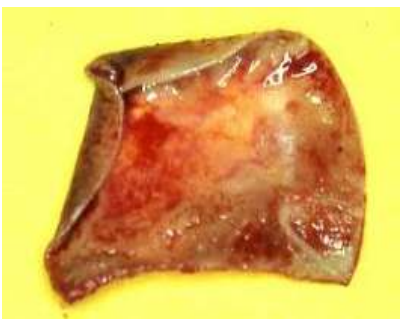

C.

Fig. 4. Failure of a GBR procedure due to premature exposure and infection of an e-PTFE membrane three weeks following membrane placement. a. soft tissue dehiscence expose the membrane to the oral environment. The membrane is contaminated with dental plaque. b. The membrane is surgically removed and the defect debrided c. clinical view of the e-PTFE membrane after removal.

With the development of bioresorbable membranes, and the increasing evidence regarding their effectiveness, the use of non-resorbable membranes has become limited to specific indications.

\section{Bioresorbable membranes}

Bioresorbable membranes offer many advantages compared with non-resorbable materials. Apart from the fact that there is no need for a second surgical intervention for removal of the membrane, they present improved soft tissue healing (Lekovic et al. 1997, 1998; Zitzmann et al. 1997); the incorporation of the membranes by the host tissues and rapid resorbtion if exposed eliminate open microstructures prone to bacterial contamination (Zitzmann et al. 1997). Bioresorbable materials that may be used for the fabrication of resorbable membranes belong to the groups of natural or synthetic polymers. The best known groups of polymers used for medical purposes are aliphatic polyesters and collagen. Over the past decade membranes are made of polyglycolide, polylactide or copolymers thereof or of collagen (Hutmacher \& Hürzeler 1995, Tal et al. 1991, 1996; Tal \& Pitaru 1992; Moses et al 2005, , Friedmann et al. 2002, von Arx et al. 2001,2005, Rothamel 2005). The qualities of a wide variety of bioresorbable membranes have been investigated experimentally and clinically (Lundgren et al. 1994; Mayfield et al. 1997; Simion et al. 1997; Zitzmann et al. 1997; Buser et al 1999, Tal et al 2008a; Tal et al 2008b). Most researchers and clinicians agree that in comparison to non-resorbable membranes, sites treated with 
bioresorbable membranes present a lower rate of complications, and have thus largely replaced the non-resorbable e-PTFE membranes becoming the standard for most clinical situations. In a few well designed studies which compared bioresorbable and nonresorbable membranes, (Zitzmann et al. 1997, 2001; Christensen et al. 2003) no significant difference was found between the two treatment modalities. It should be noted however, that Chiapasco et al. (2006), who carried out a systematic review of comparitive studies between bioresorbable and non-resorbable membranes, concluded that drawing definite conclusions was impossible due to a lack of sufficient well designed studies.

The development of bioabsorbable membranes for GTR started in the late 80's, soon after the concept had been considered accepted dental medicine; in the early 90's however, with the emerging usage of endosseous implants and the growing need for implants site development, regenerative barriers, especially bioabsorbable membranes, received more attention. Therapeutic success, complications and failures were reported, most of which dealing with inflamatory reactions in the tissues adjacent to some bioresorbable membranes, (Sandberg et al. 1993; Piatelli et al. 1995;Aaboe et al. 1998; Kohal et al. 1999; Schliephake and Krachtl. 1997).

\section{Developing collagen membranes}

Among the different materials which were experimented and clinically examined for their potential application as regenerative tissue barriers, collagen appeared to be an optimal choice and was considered to meet most requirements expected from bioabsorbable membranes. Collagens are a family of proteins with a well determined triple helical configuration. Among these proteins, collagen Type I is most prevalent, constituting approximately $25 \%$ of the body's proteins and about $80 \%$ of the connective tissue proteins. Collagen Type I polymerizes to form aggregates of fibers and bundles. Collagens are continuously remodeled in the body by degradation and synthesis. Type I collagen is degraded only by a specific enzyme - collagenase, and is resistant to any non-specific proteolytic degradation. Collagen biocompatibility, biodegradability and low immunogenicity render it advantageous for extensive application in pharmaceutical or biotechnological disciplines.

Collagen is a weak antigen and most of its antigenicity resides in the tellopeptides nonhelical terminals of the molecule. These terminals may be removed by enzymes such as pepsin, producing atellocolagen. Atellocolagen's weak antigenicity and weak immunogenicity (Cooperman and Michaeli 1984; Schlegel et al 1997). As well as its relative resistance to degradation, make collagen an optimal choice for implantable devices. Additional advantages that it possess are hemostasis, chemotaxix of periodontal ligament and gingival fibroblasts (Postlethwaite et al 1978, Yaffe et al 1984, Locci et al 1997), easy manipulation and ability to augment tissue thickness (Tal et al 1996). To the best of the author's knowledge, cross-linked medical collagen was first introduced for the purpose of guided tissue barriers in 1984 (Chu 1985, 1987). Using type I and type III dermal bovine collagen, cross linked with Glutaraldehyde (Collagen Inc. Palo Alto, CA) Becker and Tal (1984 - unpublished) have successfully examined the application of collagen membranes on class II furcation lesions in the lower mandibular molar (Fig. 5). It is noteworthy however that extreme care should be taken to avoid any remnants of amids or aldehydes in the final 
products since if left behind, these may induce a severe inflammation and damage to the peripheral tissues (Fig.6). Further laboratory improvements, turned this gluteraldehyde cross-linked collagen membranes into a safe and effective device (Pfeifer et al 1989; van Swol et al 1993). The main limitation of this membrane (Periogen, Collagen Inc. Palo Alto, CA) was a relative rapid absorbtion time varying from $4-8$ weeks.

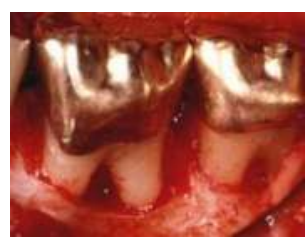

a.

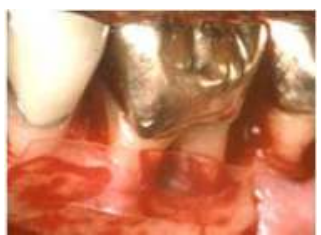

b.

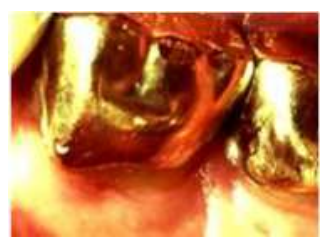

C.

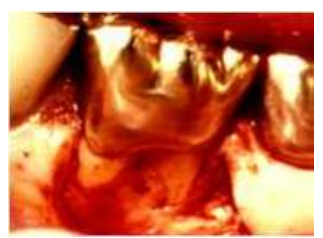

d.

Fig. 5. Clinical presentation of a class II Furcation lesion in a lower first molar tooth treated with gluteraldehyde cross-linked type I bovine collagen membrane. a. furcal defect is carefully debrided $b$. membrane is placed to seal the class II lesion c. clinical view 1 year after surgery $\mathrm{d}$. one year re-entry presents impressive regeneration of the lesion. (Becker and Tal, 1984; unpublished).

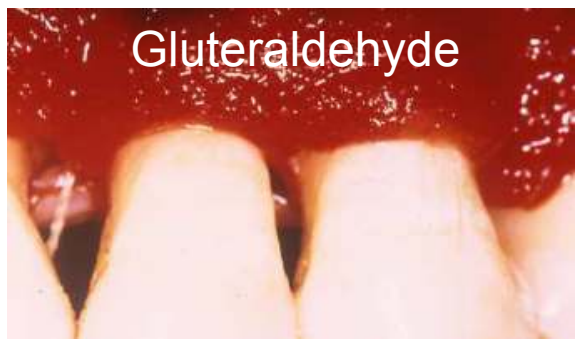

Fig. 6. Severe inflammatory gingival reaction in a patient in whom a prototype glutaraldehyde cross-linked bovine collagen membrane was placed beneath the buccal gingiva of the upper front segment, in an attempt to treat gingival recession. The clinical assumption was that gluteraldehyde remnants left after the cross-linking process were the cause for this severe tissue reaction.

\subsection{Ribose induced cross linking of medical collagen}

Since the resistance of collagen fibrils towards degradation directly relates to the density of the intermolecular cross-links, various collagen cross-linking methods have been used including aldehyde fixatives and imides and treatments such as hydration and radiations. The main drawbacks of such treatments were toxicity and inability to accurately control the degree of cross-linking. In 1988 Tanaka et al. described a novel technique to cross-link collagen that is safe and clinically effective. Briefly, their invention was based on the fact that a glycated collagen-based matrix may be prepared by non-enzymatic glycosylation of native collagen fibrils to irreversibly cross-link collagen polypeptide chains. The sugars employed as cross-linking agents, especially D-ribose, are typically non-toxic and nonimmunogenic. Since the degree of cross-linking correlates well with mechanical and biodegradation characteristics of the collagen matrix, the matrix can be readily bio-stabilized 
as desired by monitoring the degree of cross-linking during the procedure (Fig. 7). It has been suggested that ribose sugar, practically allows an unlimited degree of cross-linking providing a collagen barrier which is extremely resistant to enzymatic degradation. Clinically, cross-linked collagen membranes retain integrity for longer periods of time (Paul et al. 1992).

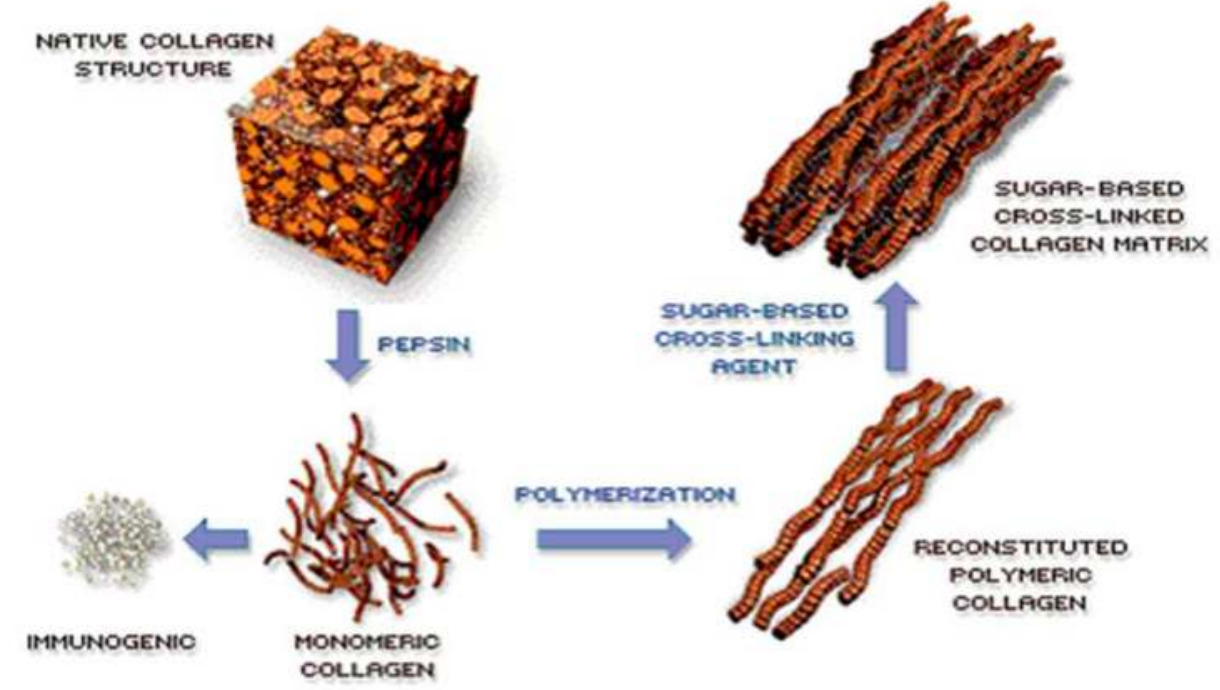

Fig. 7. Synthetic production of Enzymatic cross-linked medical collagen (modified from Colbar Life Science LTD. Ramat Hasharon, Israel.

\subsection{Bilayered collagen membrane with an internal polylactide layer}

Experimental investigations showed that degradation of collagen membranes may start within 4 days to 4 weeks after membrane placement (Zhao et al. 2000; Owens \& Yukna 2001). It was therefore questionable whether rapidly degraded membranes can successfully serve as tissue barriers for GBR. In search for different techniques to delay membrane degradation, von Arx et al (2002) hypothesized that combining a bilayer collagen membrane with an internal polylactide layer may prolong its barrier function, as well as enhance the mechanical properties of this hybrid membrane. They evaluated a prototype biodegradable bioresorbable collagen-polylactide hybrid membrane and compared it to ePTFE membrane placed at similar sites in the canine. Histological and histomorphometrical analysis of 2 months specimens, and percentage calculations for areas showing bone regeneration showed that ePTFE sites healed significantly better than the experimental membrane sites with $53 \%$ - 96.9\% bone regeneration compared to $57 \%$ $85 \%$ respectively. The experimental membrane induced moderate infiltration of lymphocytes and plasma cells adjacent to empty spaces corresponding to polylactide fragments. In addition, these reactions appeared to provoke subsequent resorption of newly formed bone. No such findings were seen in ePTFE sites. The authors concluded that the prototype membrane could not be recommended for clinical use. 


\subsection{Chemical cross-linked porcine type I and III collagens}

In an ongoing search for an improved collagen membrane which combines optimal biodegradation over time, high vascularization, favorable tissue integration, and low foreign body reaction, Rothamel et al (2005) compared the biodegradation of differently cross-linked collagen membranes in rats applying the above mentioned parameters. Five commercially available and three experimental membranes (VN) were included: (1) BioGide (BG) (noncross-linked porcine type I and III collagens), (2) BioMend (BM), (3) BioMendExtend (BME) (glutaraldehyde cross-linked bovine type I collagen), (4) Ossix (OS) (enzymatic-cross-linked bovine type I collagen), (5) TutoDent (TD) (non-cross-linked bovine type I collagen, and (68) $\mathrm{VN}(1-3)$ (chemical cross-linked porcine type I and III collagens). Specimens were randomly allocated in unconnected subcutaneous pouches on the back of Wistar rats. Histological examination and histometrical evaluation of explanted specimens representing $2,4,8,16$, and 24 weeks showed that the highest vascularization and tissue integration was noted for BG followed by BM, BME, VN and TD, while OS exhibited none. Subsequently, biodegradation of BG, BM, BME and VN was faster than TD. Ossix showed only a minute amount of superficial biodegradation 24 weeks following implantation. Biodegradation of TD, BM, BME, and VN was associated with the presence of inflammatory cells. Within the limits of this study, it was concluded that cross-linking of bovine and porcine-derived collagen types I and III was associated with prolonged biodegradation, decreased tissue integration and vascularization, and in case of TD, BM, BME and $\mathrm{VN}$ foreign body reactions (Fig 8).

Tissue Integration, Vascularization

$\begin{array}{ll}\text { BioGide } & \sim 2 \text { - } 4 \text { weeks } \\ \begin{array}{l}\text { BioMend } \\ \text { BioMendExtend }\end{array} & \sim 4 \text { - } 8 \text { weeks } \\ \text { Tutodent } & \sim 8 \text { - } 16 \text { weeks } \\ \text { VN } & \sim 8 \text { - } 16 \text { weeks } \\ \text { Ossix } & >24 \quad \text { weeks }\end{array}$

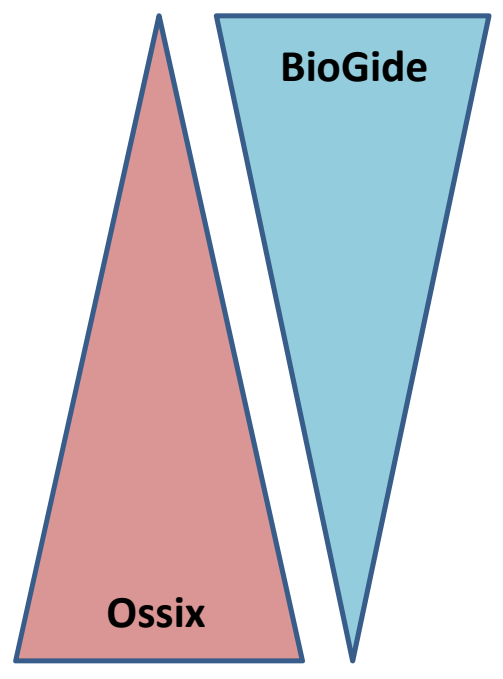

Biodegradation, foreign body reactions

Fig. 8. Prolonged biodegradation seems to be associated with tissue integration, vascularization, foreign body reactios and frequency of tissue dehiscence. Partially modified from Rothamel et.al.(2005). 


\section{Collagen barrier membranes exposed to the oral environment by spontaneous mucosal dehiscence}

Most commercially available collagen barriers have extensively been investigated in both animal models, (Pfeifer et al. 1989; Tal et al. 1991, 1996; Hyder et al. 1992; Tal \& Pitaru 1992; Crigger et al. 1996) and human studies (Van Swol et al 1993; Al Arrayed et al. 1995; Zitzmann et al. 1997; Tal 1998, 2004) presenting comparable clinical results to nonresorbable membranes (Cortellini et al. 1996; Caffesse et al. 1997). It is generally agreed that collagen membranes show a lower incidence of spontaneous exposure to the oral environment compared with non-resorbable membranes, and unlike non-resorable membranes, soft tissue healing following exposure of collagen membranes involves no infection (Friedmann et al. 2002; Moses et al. 2005). In a comparative study between prematurely exposed non-resorbable membranes (ePTFE), non-cross-linked collagen membranes (BioGide) and cross-linked collagen membranes (Ossix), the latter were claimed to be superior, and capable of supporting healing (Moses et al. 2005). This finding was partially explained by the authors' impression that in prematurely exposed cases, the cross-linked collagen membranes has the capacity to withstand bacterial collagenolytic degradation while facilitating soft tissue healing over the exposed membranes (Moses et al. 2005). In an attempt to better understand collagen barrier bio-durability and integrity in sites treated with cross-linked and non-cross-linked collagen barrier membranes, Tal et al (2008a) have clinically and histologically investigated GBR treated sites showing spontaneous mucosal perforations over barrier membranes in humans. In 52 patients, bony defects were grafted with xenograft and covered with collagen resorbable barrier membranes: 26 with cross-linked collagen membranes (Ossix $\left.{ }^{\mathrm{TM}}\right)$ and 26 with non-crosslinked collagen membranes (BioGide ${ }^{\circledR}$ ) (Fig.9). Post-surgical spontaneous mucosal perforations and membrane exposures were recorded. Surgical sites were monitored for 6 months before implant placement.

During implant placement procedure, full thickness soft tissue discs, $3 \mathrm{~mm}$ in diameter, were punched out from $18 \mathrm{Ossix}^{\mathrm{TM}}$ and 18 BioGuide ${ }^{\circledR}$ sites for histologic examination. Of the 52 sites, 33 were intact and $19(36.5 \%)$ were associated with spontaneous membrane exposure: $13(50 \%)$ were in Ossix ${ }^{\mathrm{TM}}$ sites and $6(23.1 \%)$ in BioGuide ${ }^{\circledR}$ sites $(\mathrm{p}<0.05)$. Perforation sites clinically healed within 2-4 weeks over both CL and NCL membranes. Histologically, Ossix membranes were intact in all 9 non-perforated sites, but in the perforated Ossix ${ }^{\mathrm{TM}}$ sites, membranes were interrupted in 5 and undetected in four. BioGuide ${ }^{\circledR}$ membranes were undetected in all 18 specimens examined. In 3 non-perforated Ossix membrane sites, ossification was associated with or within the membrane. It was concluded that Ossix ${ }^{\mathrm{TM}}$ membranes were more resistant to tissue degradation than BioGide ${ }^{\circledR}$. At non-perforated sites, Ossix ${ }^{\mathrm{TM}}$ membranes maintained integrity during the 6 months study period of time while BioGide® membranes disintegrated (Fig.10).

Neither CLM (Ossix ${ }^{\mathrm{TM}}$ ) nor NCLM (BioGide $\left.{ }^{\circledR}\right)$ were resistant to degradation when exposed to the oral environment. Ossix ${ }^{\mathrm{TM}}$ membranes were associated with a significantly higher incidence of tissue perforations compared with BioGide $® e$ membranes (Fig. 11).

There is no satisfactory explanation for the increased incidence of spontaneous exposure incidence at CLM treated sites compared with NCLM sites. Based on the observation that 


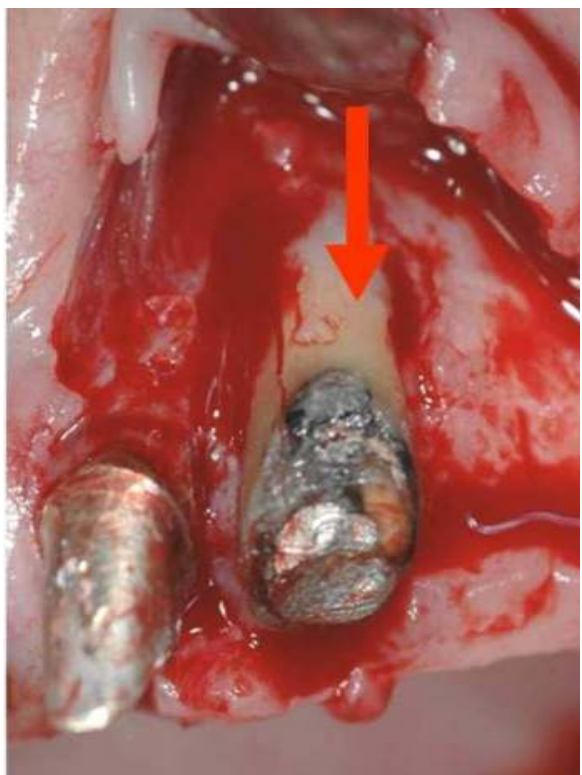

a.

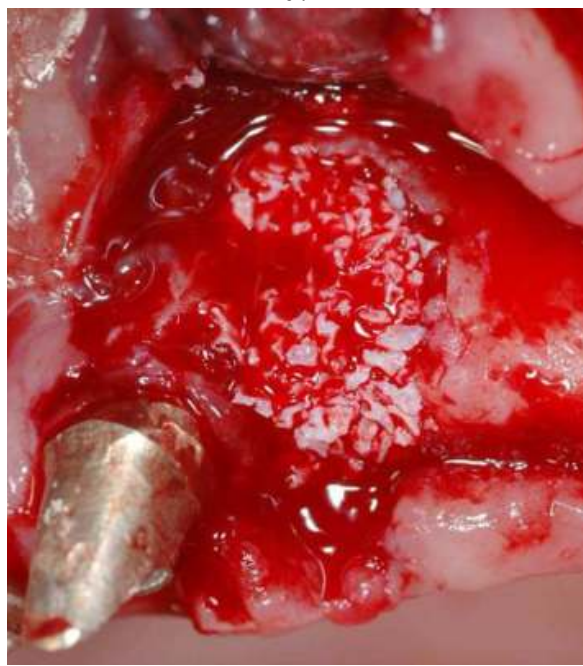

C.

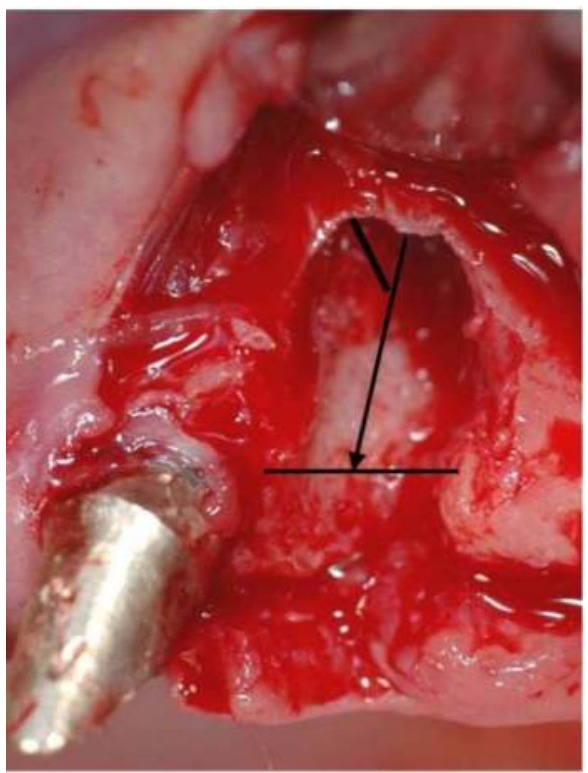

b.

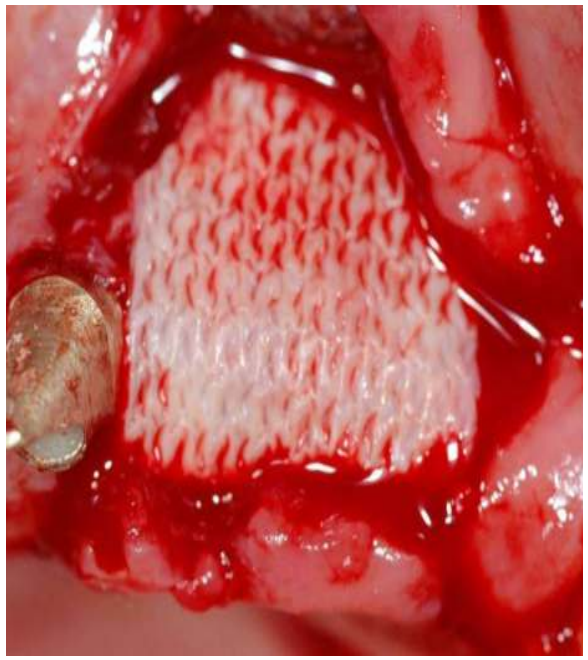

d.

Fig. 9. Clinical view of a ridge preservation procedure a. severe bone loss and complete resorbtion of the buccal plate of the alveolus associated with a longitudinal root fracture. $b$. the fresh extraction socket is debrided and measured c. the socket and bony defect are grafted with xenograft $d$. the grafted socket and defect are covered with a cross-linked collagen resorbable membrane. 
the degree of cross-linking is negatively correlated with the attachment and proliferation of PDL fibroblasts and human osteoblast-like cells observed in in-vitro cultures (Rothamel et al. 2004), the tendency of the CLM to split from the adjacent connective tissue may be due to lack of attachment between the two, and lack of membrane vascularization in the early healing phase. This phenomenon has been described by Rothamel et al. (2005) who examined the biodegadation of differently cross-linked collagen membranes in the rat and found that the Ossix $^{\mathrm{TM}}$ membrane exhibited only slight superficial vascularization and minimal surface resorption after 24 weeks compared with Bio-Gide ${ }^{\circledR}$ - a native dermal porcine collagen which showed early vascularization and over $80 \%$ resorption after 8 weeks. It should be stressed that in their animal study Rothamel et al (2005) made complete tissue closure in extra-oral subcutaneous pouches, while in our human study (Tal et. al. 2008a) a significant number of sites were spontaneously exposed to the oral environment. However, bone growth patterns shown in this study, included membrane ossification beneath the membrane leaflets and new bone growth adherent to the membrane (Figs. 12,13), suggesting high bio-compatibility between the membrane and osteoblasts ( Rothamel et al. 2004). Although this study was limited to evaluation of membrane bio-durability rather than sub-membraneous bone regeneration, it is noteworthy that a recent histological evaluation of changes during ossification and cellular events at GBR sites, has shown that in the rat maxillae, NCLM (BioGide ${ }^{\circledR}$ ) associated with defect-derived bone had integrated to such a degree that it was difficult to distinguish the membrane-derived new bone from that generated in the cavity (Taguchi et al. 2005). Based on these observations, these authors suggested that NCLM participated in the osteogenic differentiation.

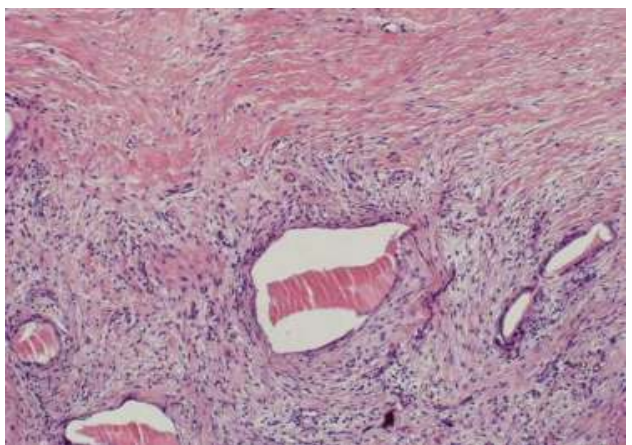

a.

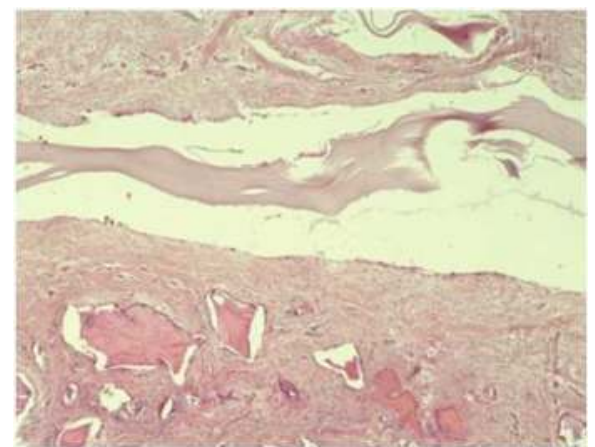

b.

Fig. 10. Histological examination of non perforated sites 6 months after membranes placement. a. the native collgen membrane (BioGide $®)$ completely disintegrated, and its location can be identified by the abrupt transition from mature supramambraneous connective tissue to young cellular submembraneous connective tissue $b$. the cross-linked membrane (Ossix $\left.{ }^{\mathrm{TM}}\right)$ maintained integrity and separates between the mature supramambraneous connective tissue and the newly established submembraneous connective tissue.

The findings described by Tal et al (2008a,b) are in agreement with the report of von Arx et al. (2005) who claimed that in the rabbit calvarium cross-linked collagen membranes clearly displayed prolonged membrane integrity compared with non-crossed-linked collagen 


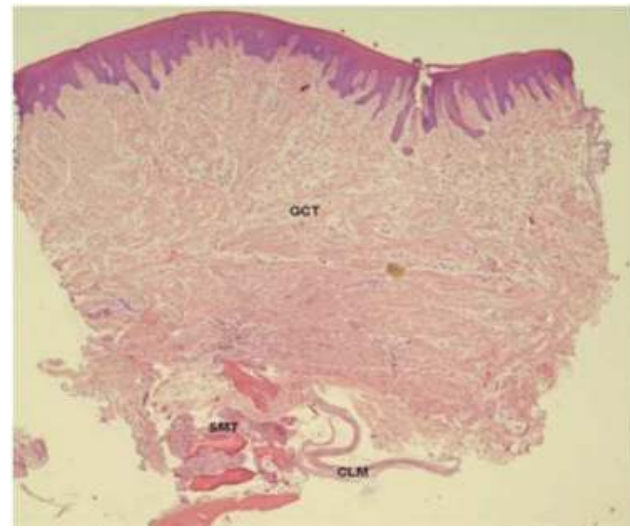

a.

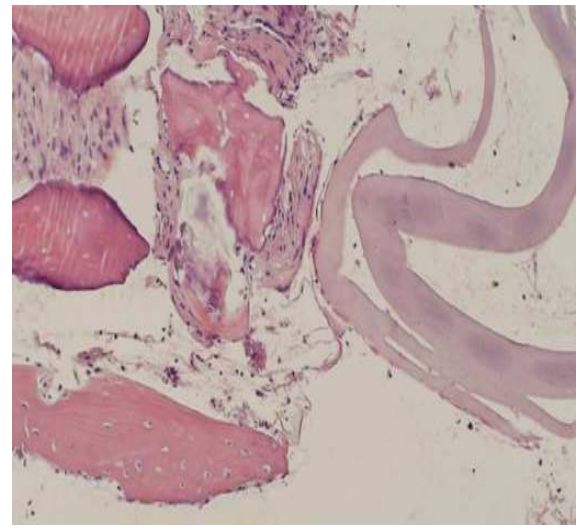

b.

Fig. 11. a. Histological aspect of CLM remnants in a perforated site. The membrane (CLM) is interrupted under the perforation and identified at the peripheral borders of the specimen (H\&E, original magnification $x 20)$. b. Higher magnification $(x 40)$ from a. showing membrane remnants (right) associated with graft particles and new bone growth.

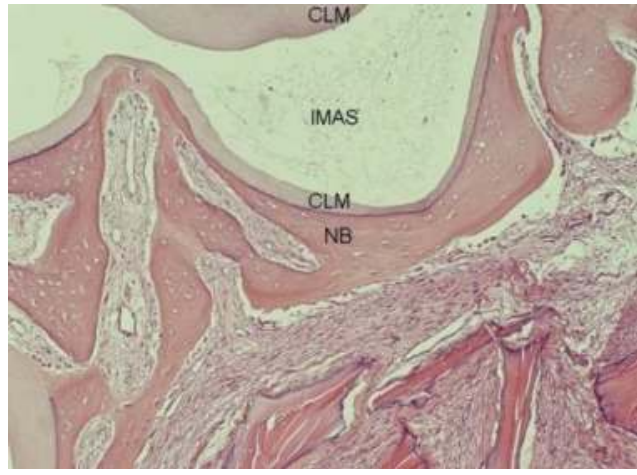

a.

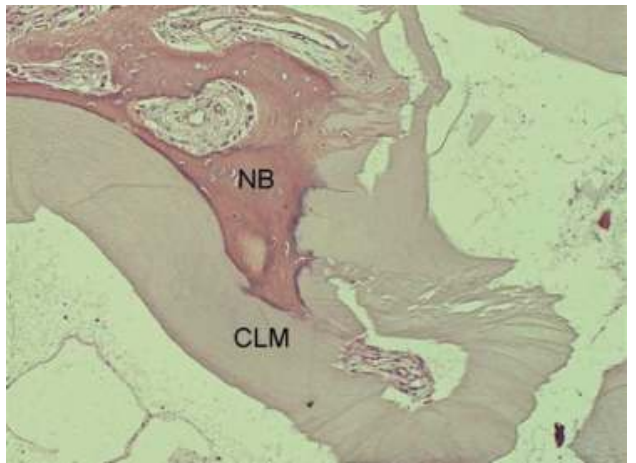

b.

Fig. 12. Histologic view of CLM remnants in a non-perforated site showing a. new bone adhered to the membrane, (H\&E, original magnification $\times 20)$. b. Occasionally bone growth is observed between the membrane leaflets penetrating the membrane (CLM) and perhaps replacing it (H\&E, original magnification $\times 40)$.

membrane. However, since their experiment was performed in a close wound, no tissue inflammatory response was involved. The studies of Tal et al $(2008 a, b)$ disagree with the interpretation that in prematurely exposed cases crossed-linked collagen membranes have "the capacity to withstand bacterial collagenolytic degradation" when exposed by soft tissue dehiscence (Moses et al. 2005). It is noteworthy that long epithelial ridges were observed in several of the healed perforation lesions associated with the crossed-linked group (FIG 14). Similar epithelial ridges have been previously described by Tal and Dayan (2000) and Tal et al.(2001) in human specimens retrieved from mucosal early perforations over submerged implants. While no scientific proof is available, it may be logical to assume that these 
epithelial ridges are remnants of epithelial down-growth that separates the exposed membrane from the perforated gingival connective tissue during early healing and before the exposed membrane resorbs.

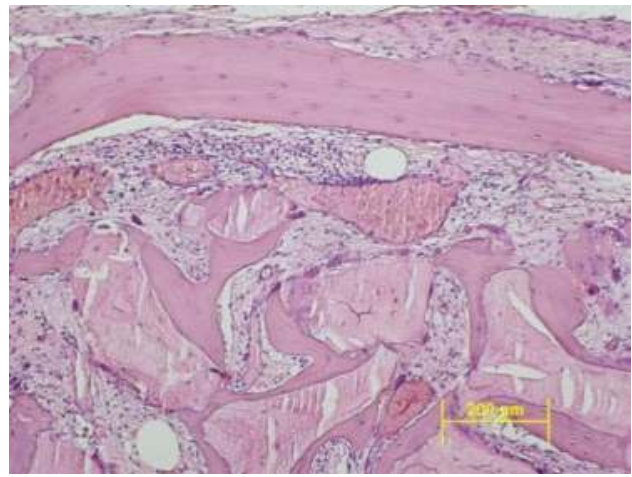

a.

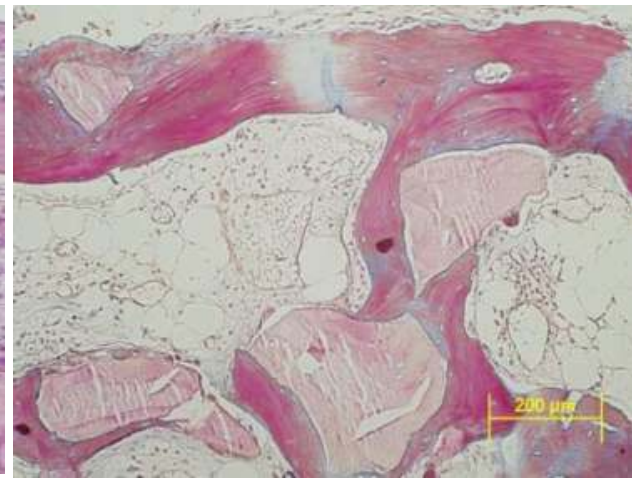

b.

Fig. 13. Histologic view of new bone adhered to an ossified CLM in a non-perforated GBR site; new bone in intimate contact with graft particles and the resorbed membrane is observed. a. H\&E, original magnification (x100). b. ( x100).

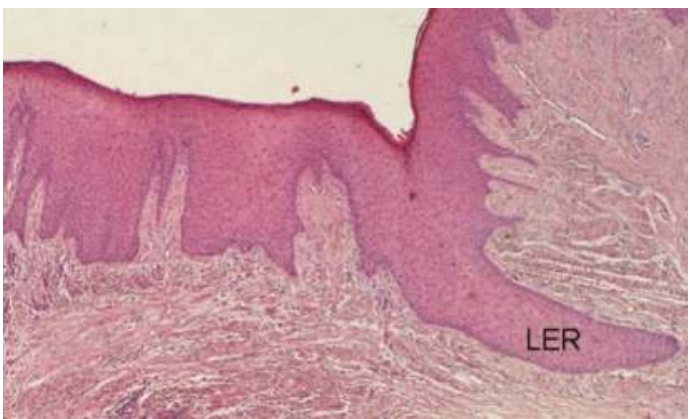

a.

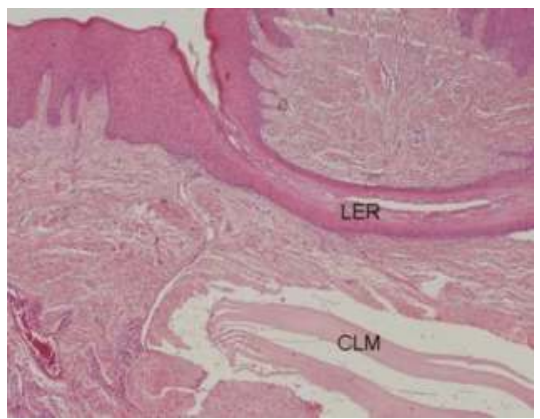

b.

Fig. 14. Histological aspect of a CLM specimen from a perforated site. Long epithelial ridge (LER) is shown at the periphery of the healed perforation. b. Long epithelial ridge (LER) is shown along the cross-linked membrane remnants (CLM), peripheral to the perforation site. A thin layer of connective tissue separates it from the membrane $(\mathrm{H} \& \mathrm{E}$, original magnification $\times 20)$.

To further understand the bio-degradation of cross-linked and non-cross-linked collagen membranes, an animal study was undertaken in which membranes were experimentally exposed to the oral environment (Tal et al 2008b). In 8 cats, 48 surgical procedures were performed, 3 along each side of the palate: 32 soft tissue perforations were made, and 16 full thickness mini-flaps were raised. Cross-linked and non-cross-linked collagen membranes discs were placed either under the perforations and peripheral mucosa and left exposed (experimental), or covered by the flaps (controls) (FIG.15). 


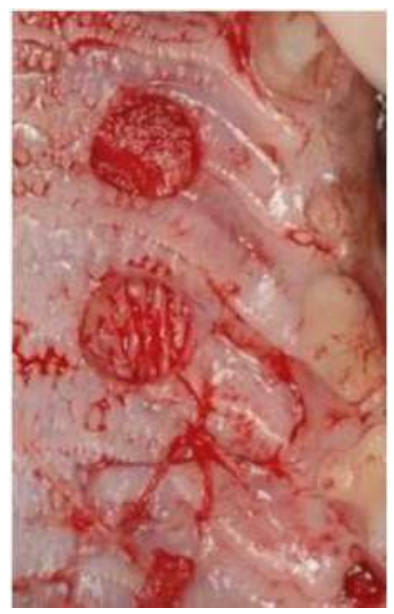

Fig. 15. Clinical view of two experimental perforation sites (top/middle) and one control site (bottom) in the cat palate. Top - Cross-linked collagen membrane disc placed under the surgically perforated mucosa; Middle - non cross-linked membrane disk placed under the surgically perforated mucosa; Bottom - membrane disk placed under surgically elevated mucosal flap and then covered (control).

The four treatment modalities were equally distributed among 8 animals. Study design provided 7 and 28 days histological specimens for each treatment modality. Histological observations revealed that cross-linked and non-cross-linked collagen membranes remained intact in the control sites during the 28 days study period. At 7 and 28 days, Cross-linked membranes appeared interrupted in 3 and 2 experimental sites, respectively, and were undetected in the remaining experimental sites. There was no statistical difference between control specimens and between CLM and NCLM of the different treatment modalities (Fig. 16). It was concluded that if covered, both cross-linked and non-cross-linked membranes were resistant to tissue degradation and maintained continuity throughout the study. However, none of the membranes was resistant to degradation when exposed to the oral environment, even after 7 days.

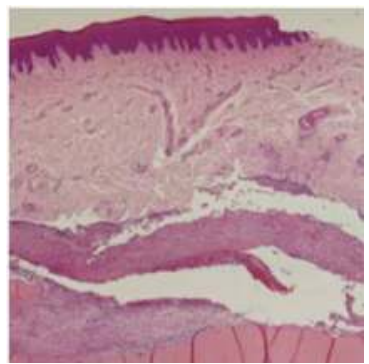

a.

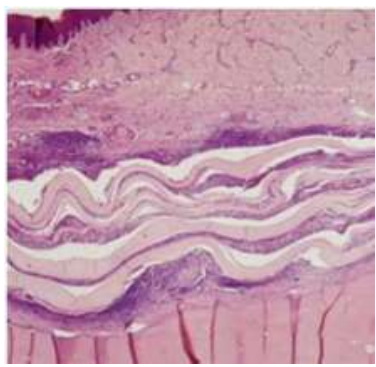

b.

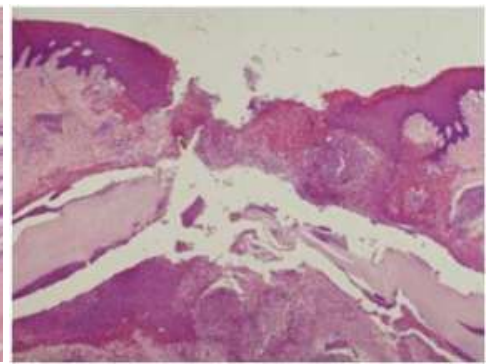

C.

Fig. 16. Histologic view of a. 28-day control NCLM specimen. The NCLM presents intimate contact with the palatal bone on the one side and with the soft connective tissue on the other side. b. 28-day control CLM specimen. The CLM presents intimate contact with the palatal 
bone on the one side and with the soft connective tissue on the other side. Connective tissue penetration between the membrane and the bone is present and membrane separation to leaflets is observed. c. 7-day experimental CLM specimen showing disintegration of the membrane under the perforation. Submembraneous granulation tissue growth and peripheral epithelial migration are observed. Inflammatory infiltrate is abundant around and between the membrane layers.

\section{Increasing the longevity of non cross-linked collagen membranes}

\subsection{Double layer native non cross-linked collagen preparation}

In search for formulas that will extend the functional activity of collagen membranes in vivo, Kozlovsky et al (2009) have evaluated the bio-degradation of a two layer preparation of a native Type I and Type III porcine collagen membrane (Bio-Gide® (BG) (Geistlich, Wolhusen, Switzerland)) and compared it with that of the commercially available single layer membrane. It has been shown that four weeks after subcutaneous implantation of BG membrane in the rat clavaria, reduction in membrane thickness combined with nearly complete biodegradation was reported (Zhao et al 2000, Rothamel et al 2005 ). When applied in surgical pouches in the palate of mongrel dogs (Owens \& Yukna 2001) moderate to complete degradation was reported 4-8 weeks following implantation. It has been suggested that application of a second layer of Bio-Gide ${ }^{\circledR}(\mathrm{BG})$ membrane (double layer technique) may reduce micro movement and improve its stabilization, thus enhancing its protective effect in the sub-membranous augmented area (von Arx \& Buser 2006). Kozlovsky et al (2009) investigated the influence of the additional layer of the barrier membrane on its durability by measuring quantitatively the in vivo degradation of barriers composed of one vs. two layers of Bio-Gide ${ }^{\circledR}$ The degree of membrane disintegration was histochemically measured based on the amount of residual membrane collagen labeled with biotin (Zohar et al. 2004) . Two circular bony defects, 5-mm in diameter, were made in the calvaria of Wistar rats. Bio-Gide ${ }^{\circledR}$ membrane 5-mm diameter discs, labeled with biotin, were placed in these defects either as a mono layer (MLM) or as a double layer (DLM) (Fig 17).

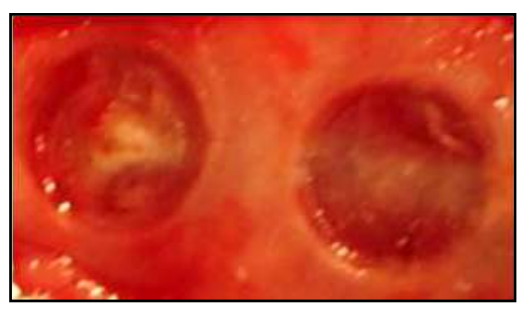

a.

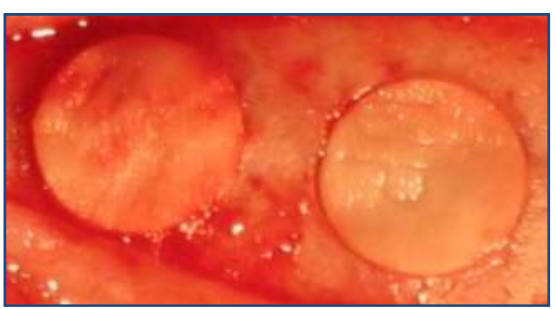

b.

Fig. 17. Photographs of the surgical procedure. (a) on the mid-line of the parietal bone, (along the sagittal suture) two similar, 5-mm diameters, approximately $1 \mathrm{~mm}$ deep) bony defects are prepared. (b) The labeled membrane discs are laid over one defect as a mono layer membrane (MLM) (right) and over the other defect as double layer membrane (DLM) (left)

Rats were sacrificed after 4 and 9 weeks and histology performed. Membranes were stained with Horseradish peroxidase-conjugated Streptavidin and Aminoethyl Carbazole as substrate for detection of biotinylated collagen. Collagen degradation in the mono layer BG 
ranked $60 \%$ during 4 weeks post application. The use of two layers of membranes resulted in a similar $(60 \%)$ resorption rate of the initial collagen content however, since the initial total collagen content in the double layer membrane was roughly twice the amount of the monolayer one, the amount of residual collagen at 4 weeks was significantly greater in the double layer sites. The rate of collagen degradation for mono layer and double layer membrane sites at 9 weeks was similar $(\sim 80 \%)$, with twofold amount of residual collagen content at the DLM sites. In addition, the residual thickness of the DLM compared with the MLM was $81 \%$ and $74 \%$ after 4 and 9 weeks respectively. Thus, it has been shown that despite of similar collagen degradation rates of both MLM and DLM, the application of a second layer of Bio-Gide ${ }^{\circledR}$ (BG) membrane (double layer technique) results in a significantly greater residual amount of collagen, at least up to 9 weeks post surgery in rats. Since membrane thickness was reduced by $\sim 30 \%$ between 4 and 9 weeks while the collagen surface area was reduced by $50-60 \%$ during that period, it may be suggested that the main pattern of resorption is an internal rather than an external one. Since the Bio-Gide ${ }^{\circledR}$ membrane is structured like an interconnected porous system with large interstices, it is most suitable for transmembranous formation of blood vessels (Schwarz et al 2006), facilitating its resorption (Rothamel et al 2004, Schwarz et al 2006). Indeed the transmembranous vascularization of the membrane was manifested histologically already 4 weeks following implantation and become well-defined through all the layers of the membrane 9 weeks following implantation (Fig 18).

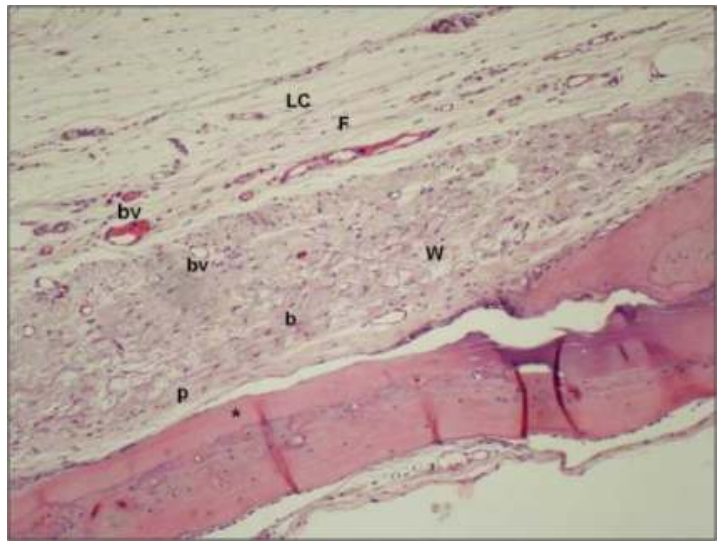

Fig. 18. Photomicrographs of hematoxylin and eosin-stained mono-layer membrane (MLM), 9-weekpost-implantation. Original magnification $\times 100$. bv- blood vessel; p- periosteum-like structure; b- eosinophilic collagen bundles; w- wavy short fibers; LC- loose connective tissue;.

Schwarz et al (2006) proposed that the vascularization process may also contribute to membrane degradation since the monocytes penetrating through the blood vessel wall may differentiate into macrophages.Kozlovsky et al (2009) reported that in spite of the difference in the thickness of the 2 membrane preparations, similar degradation rate of $80 \%$ for both membranes was measured at 9 weeks. Since the trans-membranous formation of blood vessels is essential for collagen resorption (Schwarz et al 2006), it seems that the vascularization of the double layer membrane was not impaired by its increased thickness. 
It has been claimed that increasing the density of cross links between collagen molecules has a negative effect on membrane biocompatibility (Schwarz et al 2006, Rothamel et al 2004), membrane to tissue integration and vascularization, and inhibits attachment and proliferation of PDL fibroblasts and osteoblasts (Rothamel et al. 2004, 2005). Using a second layer of resorbable, cross-linked membrane avoids these disadvantages, while extending membrane longevity. In the double layer 9 weeks membrane specimens, central intra membrane neo-ossification was clearly identified with collagen fibers embedded in the osteoid (Fig 19), confirming a phenomena previously described by others (Taguchi et al 2005, Tal et al 2008).

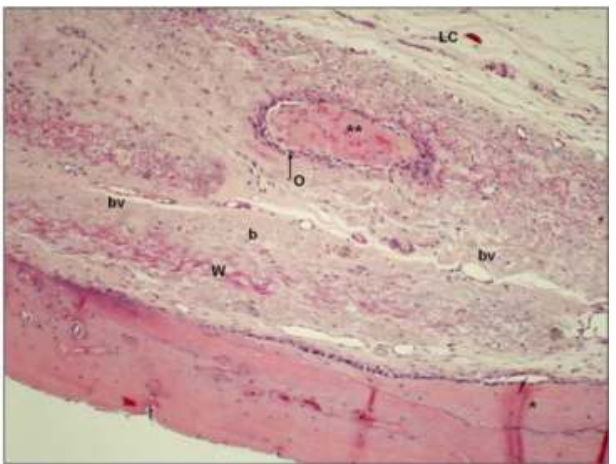

a.

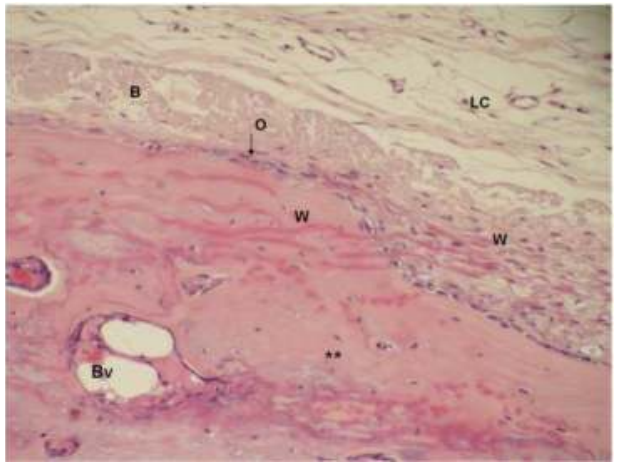

b.

Fig. 19. Photomicrographs of a double-layer membrane (DLM) membranes 9-week postimplantation. a. P-periosteum- like structure; B - eosinophilic collagen bundles; W - wavy short fibers; LC - loose connective tissue ;BV-blood vessel; O - osteoblasts. *Newly formed bone at the floor of the defect; ${ }^{* *}$ central ossification. (Hematoxylin and eosin Original magnification $\times 100)$. b. Newly formed bone $\left({ }^{* *}\right)$ adjacent to the membrane collagen bundles (B) with osteoblasts $(\mathrm{O})$ arranged on the surface. Strongly eosinophilic wave-like long collagen fibers $(\mathrm{W})$ of the membrane penetrate the osteoblastic layers and incorporate into the bone matrix of the centrally neo-ossified membrane. BV, blood vessel; LC, loose connective tissue (Hematoxylin and eosin; Original magnification $\times 200$ ).

While this finding has never been fully understood, it may be speculated that the significant increase in membrane thickness and longevity result in increasing angiogenesis and cellular population of the collagen matrix, leading to cell proliferation, differentiation and ossification.

\subsection{Increasing collagen structural stability by collagen membranes immersion and systemic tetracycline administration}

In vivo breakdown of medical collagen has thoroughly been investigated. Collagenase, the enzyme responsible for collagen biodegradation, belongs to the matrix metalloproteinases (MMP's) family of enzymes which are normally present in Mammalian tissues. Collagenase which is produced by a number of body tissues and cells, degrades collagen as part of the physiological connective tissue remodeling. Neutrophils, monocytes and fibroblasts are believed to play a major role in collagen degradation mechanisms in wounds healing by releasing MMPs (Reynolds 1994, Armstrong 2002). In vivo biodegradation of collagen 
membranes depends on collagenolytic activity; it has, therefore, been suggested that in addition to increasing the collagen structural stability by cross-linking, inhibition of MMP's may further slow down the collagen degradation (Golub et al 1998). It has been shown that Tetracycline, an antibiotic with anti-collagenolytic properties, inhibits MMPs activity (Golub at al 1997, Greenwald at al 1998). It has also been shown that the use of tetracycline-coated expanded polytetrafluoroethylene (ePTFE) barrier membranes results in additional gain of clinical periodontal attachment, most likely due to its antimicrobial activity (Zarkesh et al. 1999). Modulation of wound-healing has been successful applying sub dosage formulation of TTC, lacking antimicrobial activity while retaining the MMP inhibitory capacity. This phenomenon probably occurs due to TTC inhibition of extra-cellular MMP, likely due to its chelating activity on $\mathrm{Ca}^{++}$and $\mathrm{Zn}^{++}$ions (Golub et al. 1987). Furthermore, inflammatory cytokines including TNF-alpha, IL-1 beta, and IL-6 are markedly down-regulated in patients during treatment with tetracyclines. This phenomenon also reduces the amount of MMP's present in inflamed tissues, contributing to a reduction of the collagenolytic activity (Chung et al 1997). The effect of immersing collagen membranes in varying TTC concentration solutions on the in vitro degradation rate was evaluated (Moses et al. 2001). Membranes were incubated in either phosphate buffered saline or with TTC- $\mathrm{HCl}$ dissolved in concentrations of $5 \mathrm{mg} / \mathrm{ml}$, $50 \mathrm{mg} / \mathrm{ml}$ or $100 \mathrm{mg} / \mathrm{ml}$. The TTC impregnated and non-impregnated membranes were incubated with either bacterial collagenase or cultures of human bone lineage cells. Membrane degradation was examined on days $2,4,7$, and 14 . It was concluded that collagen membranes immersed in $50 \mathrm{mg} / \mathrm{ml}$ TTC solution exhibited the longest degradation time, both in the clostridial collagenase and the human bone cell lineage assays. Immersion in a $50 \mathrm{mg} / \mathrm{ml}$ TTC solution before implantation was, therefore, considered most effective in delaying collagen membranes degradation (Moses et al. 2001) [FIG 20].

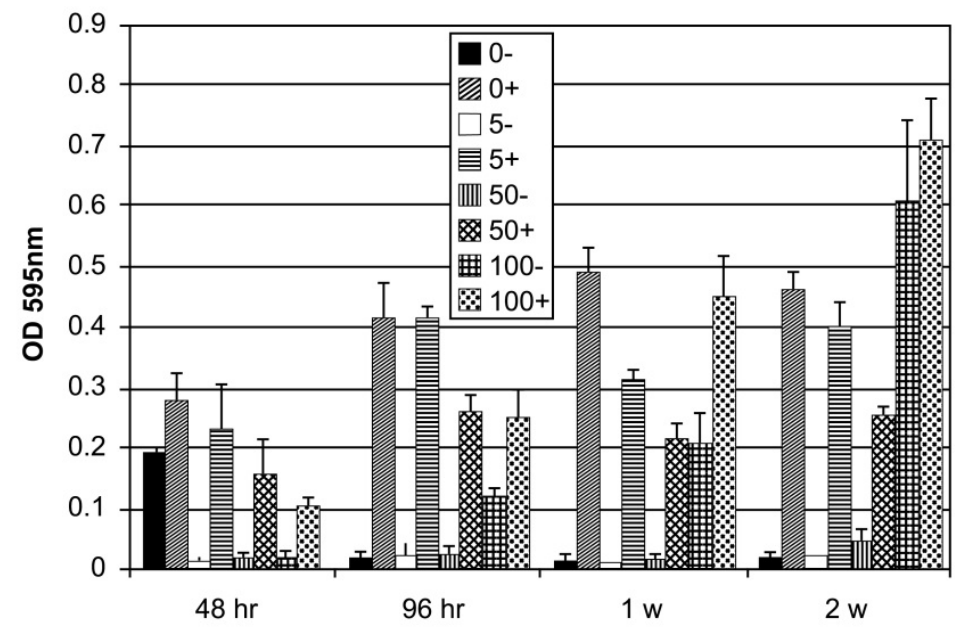

Fig. 20. Degradation of collagen membrane ( measured as optical density (OD) at the $595 \mathrm{~nm}$ wave length with $(+)$ and without $(-)$ collagenase in different Tetracycline concentration. 
These findings suggested the hypothesis that immersion of collagen in TTC prior to implantation could delay collagen degradation also in-vivo. The effect of soaking collagen membranes in different concentrations of tetracycline hydrochloride solutions (TTC) on membranes degradation rate in the rat calvaria (Zohar et al. 2004) was evaluated. Prior to implantation in the rat calvaria membranes were labeled with Biotin. The histological slides were stained with Avidin and horseradish peroxidase (HRP) to detect remnants of biotinylated collagen. Staining intensity was correlated to the amount of the remaining collagen and analyzed by image-analysis software. It was found that the staining intensity of membranes that were soaked in $50 \mathrm{mg} / \mathrm{ml}$ of TTC exhibited > 11-fold higher intensity than PBS soaked membranes (control) (Figs. 21-23). It was concluded that soaking collagen membranes in $50 \mathrm{mg} / \mathrm{ml}$ TTC solution is an effective, practical, and simple tool to reduce membrane degradation rate in vivo.

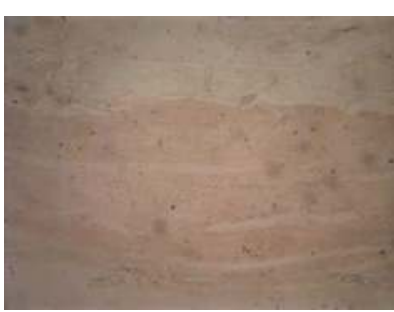

a.

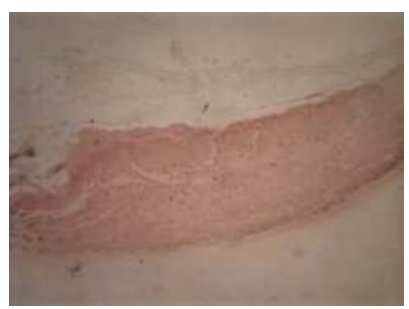

b.

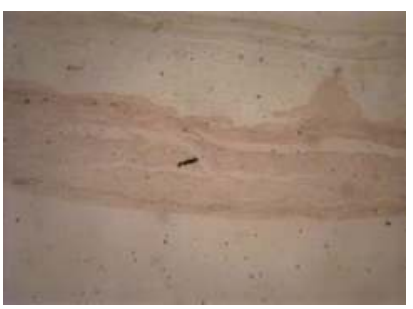

C.

Fig. 21. Histological view (x40) of the membranes 7 days after implantation with different tetracycline (TTC) concentrations. a. Phosphate-buffered saline alone $(0 \mathrm{mg} / \mathrm{mL} \mathrm{TTC})$; b. $50 \mathrm{mg} / \mathrm{mL}$ TTC. c. $100 \mathrm{mg} / \mathrm{mL}$ TTC. Collagen stained in red/brown with Avidin-BiotinHRP reaction.

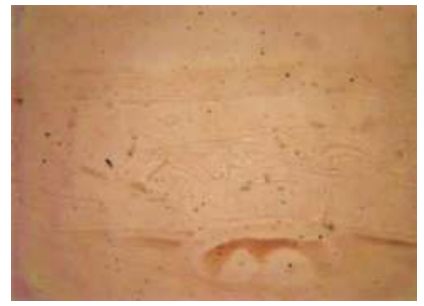

a.

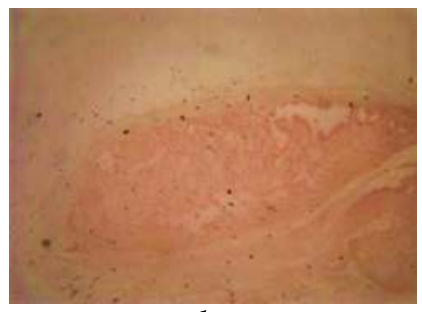

b.

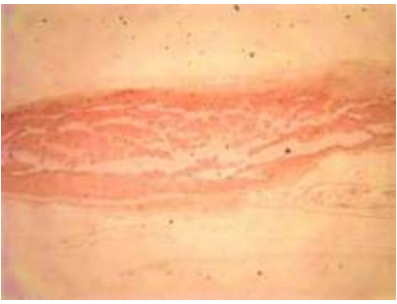

C.

Fig. 22. Histological view $(x 40)$ of the membranes 21 days after implantation with different tetracycline (TTC) concentrations. a. Phosphate-buffered saline alone $(0 \mathrm{mg} / \mathrm{mL} \mathrm{TTC})$; b. $-50 \mathrm{mg} / \mathrm{mL}$ TTC. c. $100 \mathrm{mg} / \mathrm{mL}$ TTC. Collagen stained in red/brown with Avidin-BiotinHRP reaction.

The question of whether administration of subantimicrobial dose of TTC may have an effect on the degradation of collagen membranes in vivo still remained. Evaluation of the in vivo degradation of collagen membranes treated by combined TTC immersion and systemic administration in the rat have showed that immersion of collagen membranes in TTC solution prior to their implantation and systemic administration of TTC significantly decreased membranes' degradation (Figs. 24, 25). It was therefore concluded that this 
technique may offer a treatment alternative to reduce bio-degradation and enhance biodurability of certain collagen membranes.(Moses et al. 2010).

\section{Membrane (pixels)}

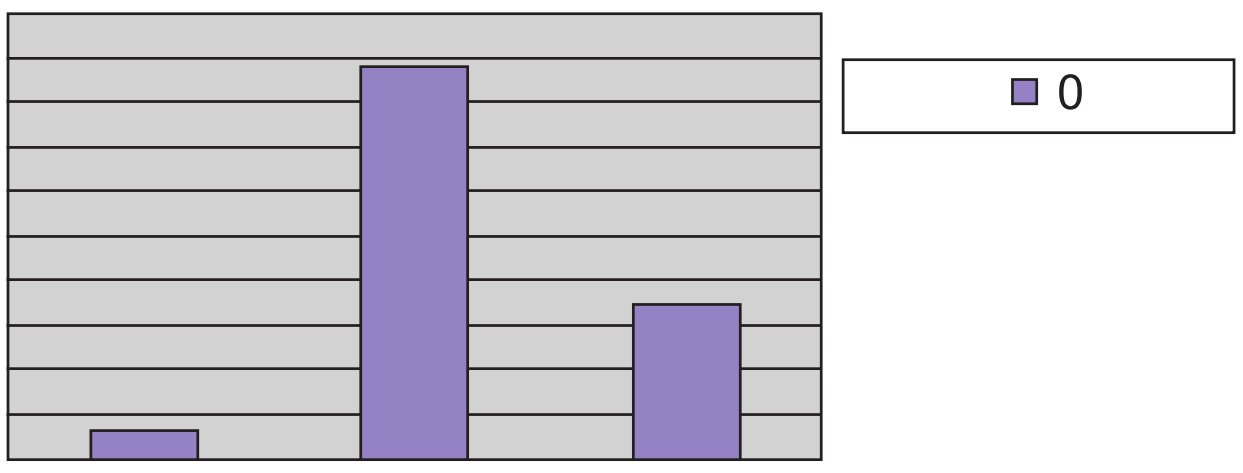

Fig. 23. Color intensity of biotinylated material as measured by number of colored pixels within collagen membrane discs from all 3 groups, 3 weeks.

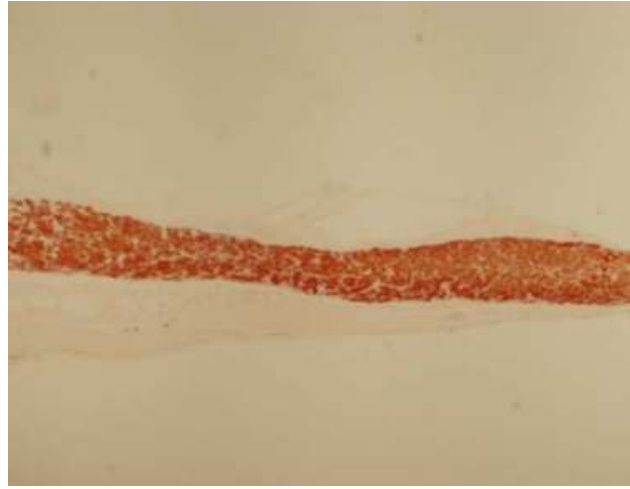

a.

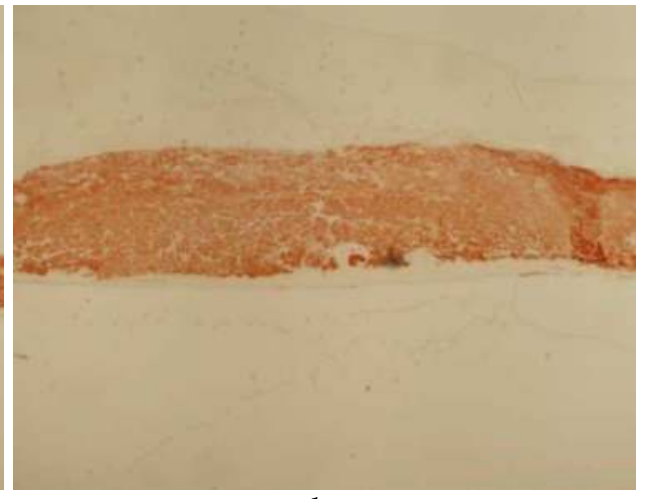

b.

Fig. 24. Histological view (x40) of the membranes 21 days after implantation with different tetracycline (TTC) concentrations with systemic administration of TTC. a. Phosphatebuffered saline alone $(0 \mathrm{mg} / \mathrm{mL}$ TTC); b. $50 \mathrm{mg} / \mathrm{mL}$ TTC. Collagen stained in red/brown with Avidin-Biotin-HRP reaction. 


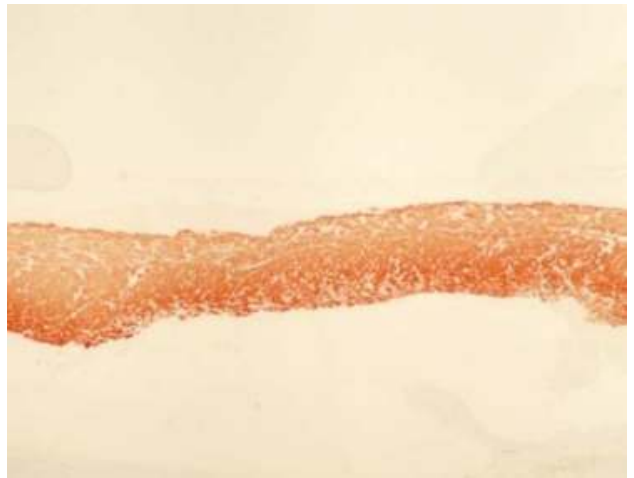

a.

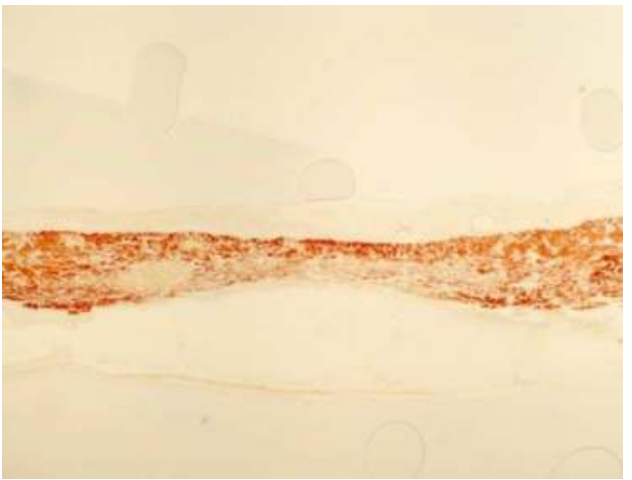

b.

Fig. 25. Histological view $(x 40)$ of the membranes 21 days after implantation with different tetracycline (TTC) concentrations without systemic administration of TTC: a. Phosphatebuffered saline alone $(0 \mathrm{mg} / \mathrm{mL}$ TTC); $2.50 \mathrm{mg} / \mathrm{mL}$ TTC. b. Collagen stained in red/brown with Avidin-Biotin-HRP reaction.

\section{Membrane supporting materials}

Publishd reports have shown that a wide range of membrane supporting materials are suitable fulfilling the requirements set, making harvesting of autogenous bone unnecessary for most procedures (See Chapters 11-14). It has been shown that in self membrane-supporting defects, where there is no need to support the membrane in order to provide space, tissue regeneration is superior to that achieved by using membrane supporting agents; in fact, the optimal osteoconductive membrane supporting material is one that interferes the least with bone regeneration within the membrane occluded space i.e. blood clot (Fig. 26). Among many materials, deproteinized bovine bone mineral, a fully synthesized homogenous hydroxyapatite and beta tricalcium phosphate, and demineralized and mineralized freezed

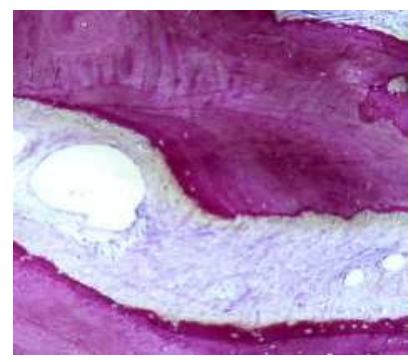

a.

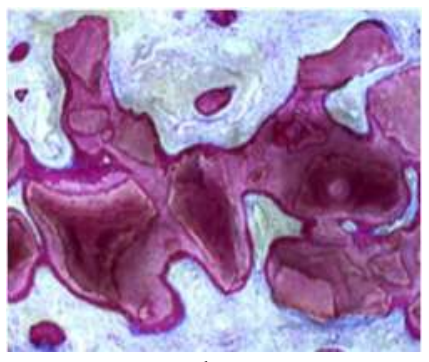

b.

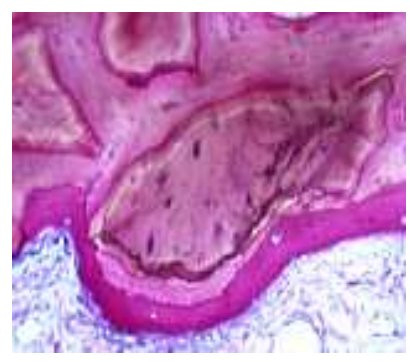

C.

Fig. 26. Experimental guided periodontal regeneration in the dog. a. new bone growth (above) in a membrane provided space filled with natural coagulum. New cementum (below) and separating periodontal ligament were also regenerated. b. GTR of the same space filled with deproteinized Bovine Bone Mineral. Paticles of the xenograft intimately surrounded by bone are observed c. higher magnification from $b$. showing a particle of deproteinized Bovine Bone Mineral intimately surrounded by new bone. 
dried bone allografts, consistently demonstrated satisfactory clinical results. While this statement is applicable for for osteoconductive materials, current research is focused on the application of growth and differentiation factors - natural proteins and polypeptides that regulate tissue regeneration. To learn more about these, the reader is referred to chapters 1-5.

\section{Conclusions}

Bioresorbable and non-resorbable membranes can successfully be used for bone regeneration. Bioresorbable membranes generally show better clinical performance compared with non-resorbable membranes and are the barriers of choice wherever possible. The parameters for selecting membranes also include mechanical properties, risk for spontaneous early exposure and ease of clinical handling. The search for improved barriers is underway; presently, collagen's biocompatibility, biodegradability and low immunogenicity render it advantageous for application in pharmaceutical or biotechnological disciplines in general, and in guided bone regeneration in particular. Among the membranes examined by our group Ossix $\mathrm{TM}^{*}$ (heavily cross-linked collagen) was found to be the most resistant to biodegradeation but showed the least tissue integration and vascularization, while BioGide (native, non-cross-linked collagen) presented high tissue integration and vascularization. Clinically, Ossix ${ }^{\mathrm{TM}^{*}}$ was associated with a higher rate of soft tissue dehiscence followed by rapid resorbtion following membrane exposure to the oral environment.

\section{Acknowledgement}

Production of this chapter was supported by The Gerald A Niznick Chair of Implantology.

\section{References}

Aaboe, M., Pinholt, E.M., Schou, S. \& Hjørting-Hansen, E. (1998). Incomplete bone regeneration of rabbit calvarial defects using different membranes. Clinical Oral Implants Research 9, 313-320.

Al Arrayed, F., Adam, S., Moran, J. \& Dowell, P. (1995) Clinical trial of cross-linked human type I collagen as a barrier material in surgical periodontal treatment. Journal of Clinical Periodontology 22, 371-379.

Armstrong DG, Jude EB. ( 2002). The role of matrix metalloproteinases in wound healing. J Am Podiatr Med Assoc: 92:12-8.

Buch, F., Albrektsson, T. \& Herbst, E. (1986). The bone growth chamber for quantifi cation of electrically induced osteogenesis. Journal of Orthopedic Research 4, 194-203.

Buser D., Dula, K., Hess, D., Hirt, H. P. \& Belser, U. C. (1999) Localized ridge augmentation with autografts and barrier membranes. Periodontology 2000 19, 151-163.

Caffesse, R. G., Mota, L. F., Quinones, C. R. \& Morrison, E. C. (1997) Clinical comparison of resorbable and non-resorbable barriers for guided periodontal tissue regeneration. Journal of Clinical Periodontology 24, 747-752.

${ }^{*}$ Ossix-P TM Colbar, Ramat Hasharon, Israel 
Chiapasco, M., Zaniboni, M. \& Boisco, M. (2006). Augmentation procedures for the rehabilitation of defi cient edentulous ridges with oral implants. Clinical Oral Implants Research 17 (Suppl 2), 136-159.

Christensen, D.K., Karoussis, I.K., Joss, A., Hammerle, C.H. \&Lang, N.P. (2003). Simultaneous or staged installation with guided bone augmentation of transmucosal titanium implants. A 3-year prospective cohort study. Clinical Oral Implants Research 14, 680-686.

Chu G. (1985). Process for preparing malleable collagen and the product thereof. United States Patent No. 4,557,764

Chu G. (1987). Collagen membranes for medical use. United States Patent No. 4,689,399

Chung CP, Kim DK, Park YJ, Nam KH, Lee SJ. (1997) Biological effects of drug-loaded biodegradable membranes for guided bone regeneration.bJ Periodontal Res;32:172-5

Cooperman L, Michaeli D. (1984). The immunogenicity of injectable collagen. I. A 1-year prospective study. J Am Acad Dermatol. 10:638-46

Cortellini, P., Pini Prato, G. \& Tonetti, M. S. (1996) Periodontal regeneration of human intrabony defects with bioresorbable membranes. A controlled clinical trial. Journal of Periodontology 67, 217-223.

Crigger, M., Bogle, G. C., Garrett, S. \& Gantes, B. G. (1996) Repair following treatment of circumferential periodontaldefects in dogs with collagen and expanded polytetrafluoroethylene barrier membranes. Journal of Periodontology 67, 403-413.

Dahlin, C., Linde, A., Gottlow, J. \& Nyman, S. (1988). Healing of bone defects by guided tissue regeneration. Plastic and Reconstructive Surgery 81, 672-677.

Dahlin, C., Alberius, P. \& Linde, A. (1991a). Osteopromotion for cranioplasty. An experimental study in rats using a membrane technique. Journal of Neurosurgery 74 (3), 487-491.

Friedmann, A., Strietzel, F. P., Maretzki, B., Pitaru, S. \& Bernimoulin, J. P. (2002) Histological assessment of augmented jaw bone utilizing a new collagen barrier membrane compared to a standard barrier membrane to protect a granular bone substitute material. Clinical Oral Implants Research 13, 587-594.

Gher, M.E., Quintero, G., Assad, D., Monaco, E. \& Richardson, A.C. (1994). Bone grafting and guided bone regeneration for immediate dental implants in humans. Journal of Periodontology 65, 881-991.

Golub LM, McNamara TF, D'Angelo G, Greenwald RA, Ramamurthy NS. (1987). A nonantibacterial chemically-modified tetracycline inhibits mammalian collagenase activity. J Dent Res. 7;66:1310-4

Golub LM, Lee HM, Greenwald RA, Ryan ME, Sorsa T, Salo T, Giannobile WV.(1997). A matrix metalloproteinase inhibitor reduces bone-type collagen degradation fragments and specific collagenases in gingival crevicular fluid during adult periodontitis. Inflamm Res.;46:310-9

Golub LM, Lee HM, Ryan ME, Giannobile WV, Payne J, Sorsa T. (1998). Tetracyclines inhibit connective tissue breakdown by multiple non-antimicrobial mechanisms. Adv Dent Res.8;12(2):12-26.

Gotfredsen, K., Nimb, L., Buser, D. \& Hjørting-Hansen, E. (1993). Evaluation of guided bone regeneration around implants placed into fresh extraction sockets. An experimental study in dogs. Journal of Oral and Maxillofacial Surgery 51, 879-884. 
Gottlow, J. (1993). Guided tissue regeneration using bioresorbable and non-resorbable devices: Initial healing and longterm results. Journal of Periodontology 64, 1157-1165.

Greenwald RA, Golub LM, Ramamurthy NS, Chowdhury M, Moak SA, Sorsa T. (1998). In vitro sensitivity of the three mammalian collagenases to tetracycline inhibition: relationship to bone and cartilage degradation. Bone.; 22:33-8

Hämmerle, C.H.F., Brägger, U., Schmid, B. \& Lang, N.P. (1998). Successful bone formation at immediate transmucosal implants. International Journal of Oral $\mathcal{E}$ Maxillofacial Implants 13, 522-530.

Hammerle, C.H., Jung, R.E. \& Feloutzis, A. (2002). A systematic review of the survival of implants in bone sites augmented with barrier membranes (guided bone regeneration) in partially edentulous patients. Journal of Clinical Periodontology 29 (Suppl 3), 226-231; discussion 232-223.

Hardwick, R., Scantlebury, T.V., Sanchez, R., Whitley, N. \& Ambruster, J. (1994). Membrane design criteria for guided bone regeneration of the alveolar ridge In: Buser, D., Dahlin, C. \& Schenk, R.K., eds. Guided Bone Regeneration in Implant Dentistry. Chicago, Berlin: Quintessence, pp. 101-136.

Hutmacher, D. \& Hürzeler, M.B. (1995). Biologisch abbaubare Polymere und Membranen für die gesteurte Gewebe- und knochenregeneration. Implantologie 1, 21-37.

Hyder PR, Dowell P, Dolby AE. (1992) Freeze-dried, cross-linked bovine type I collagen: Analysis of properties. J Periodontol;63:182-186.

Ilizarov, G.A. (1989a). The tension-stress effect on the genesis and growth of tissues: Part I. The infl uence of stability of fi xation and soft tissue reservation. Clinical Orthopaedics 238, 249-281.

Ilizarov, G.A. (1989b). The tension-stress effect on the genesis and growth of tissues: Part II. The infl uence of the rate and frequency of distraction. Clinical Orthopaedics 239, 263-285.

Karring, T., Nyman, S. \& Lindhe, J. (1980). Healing following implantation of periodontitis affected roots into bone tissue. Journal of Clinical Periodontology 7, 96-105.

Kohal, R.J., Trejo, P.M., Wirsching, C., Hürzeler, M.B. \& Caffesse, R.G. (1999a). Comparison of bioabsorbable and bioinert membranes for guided bone regeneration around non-submerged implants. An experimental study in the mongrel dog. Clinical Oral Implants Research 10, 226-237.

Kostopoulos, L. \& Karring, T. (1994). Augmentation of the rat mandible using guided tissue regeneration. Clinical Oral Implants Research 5, 75-82.

Kozlovsky A, Aboodi G, Moses O, Tal H, Artzi Z, Weinreb M, Nemcovsky CE. (2009).Biodegradation of a resorbable collagen membrane (Bio-Gide) applied in a doublelayer technique in rats.Clin Oral Implants Res. 2009 Oct;20(10):1116-23

Lekholm, U., Adell, R. \& Lindhe, J. (1986). Marginal tissue reactions at osseointegrated titanium fi xtures. (II) A crosssectional retrospective study. International Journal of Oral \& Maxillofacial Surgery 15, 53-61.

Lekovic, V., Kenney, E.B., Weinlaender, M., Han, T., Klokkevold, P.R., Nedic, M. \& Orsini, M. (1997). A bone regenerative approach to alveolar ridge maintenance following tooth extraction. Report of 10 cases. Journal of Periodontology 68, 563-570. 
Lekovic, V., Camargo, P.M., Klokkevold, P.R., Weinlaender, M., Kenney, E.B., Dimitrijevic, B. \& Nedic, M. (1998). Preservation of alveolar bone in extraction sockets using bioabsorbable membranes. Journal of Periodontology 69, 1044-1049.

Locci P, Calvitti M, Belcastro S, Pugliese M, Guerra M, Marinucci L, Staffolani N, Becchetti E (1997).Phenotype expression of gingival fibroblasts cultured on membranes used in guided tissue regeneration. J Periodontol. 68:857-63.

Lundgren, D., Mathisen, T. \& Gottlow, J. (1994a). The development of a bioresorbable barrier for guided tissue regeneration. The Journal of the Swedish Dental Association 86, 741-756.

Mayfield, L., Nobréus, N., Attström, R. \& Linde, A. (1997). Guided bone regeneration in dental implant treatment using a bioabsorbable membrane. Clinical Oral Implants Research 8, 10-17.

Melcher AH. (1970). Repair of wounds in the periodontium of the rat. Influence of periodontal ligament on osteogenesis. Arch Oral Biol. 15,1183-204.

Melcher AH. (1976). On the repair potential of periodontal tissues. J Periodontol. 47, 256-60.

Moses, O., Pitaru, S., Artzi, Z. \& Nemcovsky, C. (2005). Healing of dehiscence-type defects in implants placed together with different barrier membranes: a comparative clinical study. Clinical Oral Implants Research 16, 210-219.

Moses, O, Nemcovsky CE, Tal H, Zohar R. (2001) Tetracycline modulates collagen membrane degradation in vitro. J Periodontol.;72:1588-93

Moses, O, Frenkel T, Tal H, Weinreb M, Bornstein MM, Nemcovsky CE. (2010) Effect of systemic tetracycline on the degradation of tetracycline-impregnated bilayered collagen membranes: an animal study. Clin Implant Dent Relat. Res. 12(4):331- 337.

Nyman, S., Karring, T., Lindhe, J. \& Planten, S. (1980). Healing following implantation of periodontitis affected roots into gingival connective tissue. Journal of Clinical Periodontology 7, 394-401.

Nyman SR, Lang NP.;Guided tissue regeneration and dental implants. Periodontol 2000. 1994 Feb;4:109-18. Review. No abstract available

Owens, K. W. \& Yukna, R. A. (2001) Collagen membrane resorption in dogs: Acomparative study. Implant Dentistry 10, 49-56.

Paul, B. F., Mellonig, J. T., Towle, H. J. 3rd \& Gray, J. L. (1992) Use of a collagenbarrier to enhance healing in human periodontal furcation defects. International Journal of Periodontics \& Restorative Dentistry 12, 123-131.

Pfeifer, J., Van Swool, L. M. \& Ellinger, R. (1989) Epithelial exclusion and tissueregeneration using a collagen barrier in chronic periodontal defects: Histologicalstudy. International Journal of Periodontics \& Restorative Dentistry 9, 263-273.

Piatelli, A., Scarano, A., Russo, P. \& Matarasso, S. (1995). Evaluation of guided bone regeneration in rabbit tibia using bioresorbable and non-resorbable membranes. Biomaterials 17, 791-796.

Postlethwaite AE, Seyer JM, Kang AH. (1978) Chemotactic attraction of human fibroblasts to type I, II, and III collagens and collagen-derived peptides. Proc Natl Acad Sci U S A. $75: 871-5$

Reddi, A.H. (1981). Cell biology and biochemistry of endochondral bone development. Collagen Related Research 1, 209-226. 
Reddi, A.H., Weintroub, S. \& Muthukumaran, N. (1987). Biologic principles of bone induction. Orthopedic Clinics of North America 18, 207-212.

Reynolds JJ, Hembry RM, Meikle MC. (1994) Connective tissue degradation in health and periodontal disease and the roles of matrix metalloproteinases and their natural inhibitors. Adv Dent Res.;8(2):312-9.

Rothamel, D., Schwarz, F., Sculean, A., Monika, H., Scherbaum, W. \& Becker, J. (2004) Biocompatibility of various collagen membranes in cultures of human PDL fibroblasts and human osteoblast-like cells. Clinical Oral Implants Research 15, 443449

Rothamel, D., Schwarz, F., Sager, M., Herten, M., Sculean, A. \& Becker, J. (2005) Biodegradation of differently cross-linked collagen membranes: an experimentalstudy in the rat. Clinical Oral Implants Research 16, 369-378.

Sandberg, E., Dahlin, C. \& Linde, A. (1993). Bone regeneration by the osteopromotion technique using bioabsorbable membranes. An experimental study in rats. Journal of Oral and Maxillofacial Surgery 51, 1106-1114.

Schlegel AK, Möhler H, Busch F, Mehl A. (1997) Preclinical and clinical studies of a collagen membrane (Bio-Gide). Biomaterials. 18:535-8.

Schliephake, H. \& Kracht, D. (1997). Vertical ridge augmentation using polylactic membranes in conjunction with immediate implants in periodontally compromized extraction sites: an experimental study in dogs. International Journal of Oral $\mathcal{E}$ Maxillofacial Implants 12, 325-334.

Schwarz F, Rothamel D, Herten M, Sager M, Becker J. (2006) Angiogenesis pattern of native and cross-linked collagen membranes: an immunohistochemical study in the rat. Clinical Oral Implants Research 17:403-9.

Simion, M., Baldoni, M., Rossi, P. \& Zaffe, D. (1994a). A comparative study of the effectiveness of e-PTFE membranes with and without early exposure during the healing period. International Journal of Periodontics and Restorative Dentistry 14, 167180.

Simion, M., Misitano, U., Gionso, L. \& Salvato, A. (1997). Treatment of dehiscences and fenestrations around dental implants using resorbable and nonresorbable membranes associated with bone autografts: a comparative clinical study. International Journal of Oral \& Maxillofacial Implants 12, 159-167.

Taguchi, Y., Amizuka, N., Nakadate, M., Ohnishi, H., Oda, K., Nomura, S. \& MaedaT. (2005) A histological evaluation of guided bone regeneration induced by collagenous membrane. Biomaterials 26, 6158-6166.

Tal, H. (1998) Ridge preservation and gingival augmentation. Independent Dentistry 3, 96-100.

Tal, H. (2004) Healing of osseous defects by guided bone regeneration using ribosecross linked collagen membranes. Journal of the Israel Dental Association 21, 32- 40

Tal, H., Kozlovsky A, Pitaru S, Noff M. (1991): Monolayer versus bilayer-gel coated collagen membranes for periodontal guided tissue regeneration in the canine. $J$ Periodontology 1991; abst\#61:317.

Tal, H. \& Pitaru, S. (1992) Formation of new periodontal attachment apparatus after experimental root isolation with collagen membranes in the dog. International Journal of Periodontics \& Restorative Dentistry 3, 231-242. 
Tal, H., Pitaru, S., Moses, O. \& Kozlovsky, A. (1996) Collagen gel and membrane in guided tissue regeneration in periodontal fenestration defects in dogs. Journal of Clinical Periodontology 23, 1-6.

Tal, H. \& Dayan, D. (2000) Spontaneous early exposure of submerged implants. III.Histopathology of perforated mucosa covering submerged implants. Journal of Periodontology 72, 1231-1235. Not in text

Tal, H., Artzi, Z., Moses, O., Nemcovsky, C. E. \& Kozlovsky, A. (2001) Spontaneousearly exposure of submerged endosseous implants resulting in crestal one loss: A clinical evaluation between stage I and stage II surgery. International Journal of Oral $\mathcal{E}$ Maxillofacial Implants 16, 514-521.

Tal, H., Kozlovsky A, Artzi Z., Nemcovsky, C.E. , Moses O. (2008a). Long term biodegradation of cross-linked and non-cross-linked collagen barriers in human guided bone regeneration Clinical Oral Implants Res. 19):295-302.

Tal, H., A. Kozlovsky, Z. Artzi, C.E. Nemcovsky, O. Moses (2008b). Cross-linked Crosslinked and non-cross-linked collagen barrier membranes disintegrate following surgical exposure to the oral environment: Histological study in the cat. Clinical Oral Implants19:760-6.

Tanaka S, Avigad G, Eikenberry EF, Brodsky B.(1988). Isolation and partial characterization of cross-links collagen chains dimerized by sugar-derived. J Biol Chem;263:1765017657.

Urist, M.R. (1965). Bone: formation by autoinduction. Science 150, 893-899.

Van Swol RL, Ellinger R, Pfeifer J, Barton NE, Blumenthal N.Collagen membrane barrier therapy to guide regeneration in Class II furcations in humans. J Periodontol. 1993 Jul;64(7):622-9.

von Arx, T., Cochran, D.L., Hermann, J.S., Schenk, R.K., Higginbottom, F.L. \& Buser, D. (2001). Lateral ridge augmentation and implant placement: An experimental study evaluating implant osseointegration in different augmentation materials in the canine mandible. International Journal of Oral \& Maxillofacial Implants 16, 343-354.

von Arx, T., Cochran, D. L., Schenk, R. K. \& Buser, D. (2002) Evaluation of a prototype trilayer membrane (PTLM) for lateral ridge augmentation: An experimental study in the canine mandible. International Journal of Oral \& Maxillofacial Surgery 31, 190 199.

von Arx T, Buser D. (2006). Horizontal ridge augmentation using autogenous block grafts and the guided bone regeneration technique with collagen membranes: a clinical study with 42 patients. Clinical Oral Implants Research 17:359-66.

von Arx, T., Hafl iger, J. \& Chappuis, V. (2005). Neurosensory disturbances following bone harvesting in the symphysis: a prospective clinical study. Clinical Oral Implants Research 16, 432-439.

Yaffe A, Ehrlich J, Shoshan S. (1984). Restoration of periodontal attachment employing enriched collagen solution in the dog. J Periodontol. 55:623-8.

Zarkesh N, Nowzari H, Morrison JL, Slots J (1999) Tetracycline-coated polytetrafluoroethylene barrier membranes in the treatment of intraosseous periodontal lesions. J Periodontol.;70:1008-16. 
Zhao, S., Pinholt, E. M., Madsen, J. E. \& Donath, K. (2000) Histological evaluation of different biodegradable and nonbiodegradable membranes implanted subcutaneouslyin rats. Journal of Craniomaxillofacial Surgery 28, 116-122.

Zitzmann, N.U., Naef, R. \& Schärer, P. (1997). Resorbable versus nonresorbable membranes in combination with Bio- Oss for guided bone regeneration. International Journal of Oral \& Maxillofacial Implants 12, 844-852.

Zitzmann, N.U., Schärer, P. \& Marinello, C.P. (2001). Longterm results of implants treated with guided bone regeneration: A 5-year prospective study. International Journal of Oral \& Maxillofacial Surgery 16, 355-366

Zohar R, Nemcovsky CE, Kebudi E, Artzi Z, Tal H, Moses O. (2004) Tetracycline impregnation delays collagen membrane degradation in vivo. J Periodontol. 75:1096-101. 


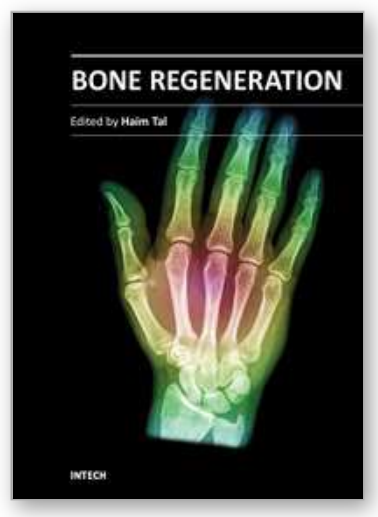

\author{
Bone Regeneration \\ Edited by Prof. Haim Tal
}

ISBN 978-953-51-0487-2

Hard cover, 340 pages

Publisher InTech

Published online 04, April, 2012

Published in print edition April, 2012

Bone is a specialized connective tissue, most prominently characterized by its mineralized organic matrix that imparts the physical properties that allow bone tissue to resist load, to support functional organs, and to protect highly sensitive body parts. Bone loss and bone damage may occur as a result of genetic conditions, infectious diseases, tumours, and trauma. Bone healing and repair, involves integrative activity of native tissues and living cells, and lends itself to the incorporation of naturally derived or biocompatible synthetic scaffolds, aimed at replacing missing or damaged osseous tissues. There are several modalities of bone regeneration including tissue engineering, guided bone regeneration, distraction ontogenesis, and bone grafting. This book concentrates on such procedures that may well be counted among the recent outstanding breakthroughs in bone regenerative therapy.

\title{
How to reference
}

In order to correctly reference this scholarly work, feel free to copy and paste the following:

Haim Tal, Ofer Moses, Avital Kozlovsky and Carlos Nemcovsky (2012). Bioresorbable Collagen Membranes for Guided Bone Regeneration, Bone Regeneration, Prof. Haim Tal (Ed.), ISBN: 978-953-51-0487-2, InTech, Available from: http://www.intechopen.com/books/bone-regeneration/bioresorbable-collagen-membranes-forguided-bone-regeneration

\section{INTECH}

open science | open minds

\author{
InTech Europe \\ University Campus STeP Ri \\ Slavka Krautzeka 83/A \\ 51000 Rijeka, Croatia \\ Phone: +385 (51) 770447 \\ Fax: +385 (51) 686166 \\ www.intechopen.com
}

\author{
InTech China \\ Unit 405, Office Block, Hotel Equatorial Shanghai \\ No.65, Yan An Road (West), Shanghai, 200040, China \\ 中国上海市延安西路65号上海国际贵都大饭店办公楼 405 单元 \\ Phone: +86-21-62489820 \\ Fax: $+86-21-62489821$
}


(C) 2012 The Author(s). Licensee IntechOpen. This is an open access article distributed under the terms of the Creative Commons Attribution 3.0 License, which permits unrestricted use, distribution, and reproduction in any medium, provided the original work is properly cited. 